\title{
Antioxidant stress and anticancer activity of peptide-chelated selenium in vitro
}

\author{
XIAN LI ${ }^{1}$, XIANJUE WANG ${ }^{1}$, GANG LIU ${ }^{1}$, YANAN XU ${ }^{1}$, XINLIN WU ${ }^{2}$, \\ $\mathrm{RU} \mathrm{YI}^{3}$, FENG JIN $^{3}, \mathrm{CHULA} \mathrm{SA}^{3}$ and XIULAN SU ${ }^{1}$ \\ ${ }^{1}$ Key Laboratory of Medical Cell Biology in Inner Mongolia, Clinical Medical Research Center, \\ The Affiliated Hospital of Inner Mongolia Medical University, Hohhot, Inner Mongolia 010050; \\ ${ }^{2}$ Department of Gastrointestinal Surgery, The Affiliated Hospital of Inner Mongolia Medical University; \\ ${ }^{3}$ Inner Mongolia Medical University, Hohhot, Inner Mongolia 010059, P.R. China
}

Received January 4, 2021; Accepted May 14, 2021

DOI: $10.3892 /$ ijmm.2021.4986

\begin{abstract}
The association between selenium and peptide in gastric cancer is an important research topic. The present study reported the facile synthesis of anticancer bioactive peptide (ACBP)-functionalized selenium (ACBP-S-Se) particles with enhanced anticancer activities and a detailed mechanistic evaluation of their ability to regulate oxidative stress in vitro. Structural and chemical characterizations were revealed by ultraviolet absorption, Fourier transform infrared, X-ray photoelectron, nuclear magnetic resonance carbon and hydrogen, energy dispersive X-ray spectroscopy and inductively coupled plasma mass spectrometry, as well as scanning electron microscopy. Sulfhydrylation modifications of ACBP were achieved with S-acetylmercaptosuccinic anhydride via chemical absorption. After the polypeptide was modified by sulfhydrylation, the ACBP chain was linked to sulfhydryl groups by amide bonds to form the ACBP-chelated selenium complex. Two gastric cancer cell lines (MKN-45 and MKN-74 cells) demonstrated high susceptibility to ACBP-S-Se particles and displayed significantly decreased proliferation ability following treatment. The results suggested that the bioactive peptide-chelated selenium particles effectively inhibited the proliferation of MKN-45 and MKN-74 cells in vitro. The genes encoding CDK inhibitor $1 \mathrm{~A}$ (CDKN1A), cyclin B1, thioredoxin $(T X N)$ and mitogen-activated protein kinase kinase kinase 5 are associated with regulation of oxidative stress, while $C D K N 1 A$ and $T X N$ protect cells by decreasing oxidative stress and promoting cell growth arrest. Therefore, ACBP-S-Se may be an ideal chemotherapeutic candidate for human cancer, especially gastric cancer.
\end{abstract}

Correspondence to: Professor Xiulan Su, Key Laboratory of Medical Cell Biology in Inner Mongolia, Clinical Medical Research Center, The Affiliated Hospital of Inner Mongolia Medical University, 1 Tongdao North Street, Hohhot, Inner Mongolia 010050, P.R. China

E-mail: xlsu@hotmail.com

Key words: anticancer bioactive peptide, selenium element, gastric cancer, antitumor agent

\section{Introduction}

Oxidative stress refers to aberrant production of active substances, including reactive oxygen species (ROS) and nitrogen free radicals, under various stress stimuli, which leads to an unbalanced physiological status or oxidative stress (OS)-associated damage via oxidation-reduction reactions (1). Previous studies revealed that ROS generated by cells under OS are involved in gastric tumorigenesis $(2,3)$.

ROS have been shown to promote gastric carcinogenesis in both clinical studies and mouse models in vivo $(4,5)$. The dysregulation of ROS promotes tumorigenesis and the development of abnormalities due to its ability to increase aberrant cell proliferation, survival and migration in vivo $(4,5)$. Moreover, aberrant production of ROS also induces DNA damage, leading to genomic instability, tumorigenicity and subsequent tumor progression (6). For example, ROS are constantly generated in cells as a consequence of endogenous metabolism, infection/inflammation and/or exposure to environmental toxins (6). If the accumulation of ROS overwhelms the death threshold, cellular apoptosis levels increase, which enhances the antitumor effects of ROS production (7). Fuloria et al (8) confirmed that ROS alleviate certain types of cancer, such as oral (9) and gastric cancer (GC) (10), and that the redox state in cells is an important factor for subsequent tumor formation potential; thus, cellular redox states are potential therapeutic targets for cancer treatment. Finally, ROS may contribute to the regulation of apoptosis (9).

Selenium (Se), with a narrow range between deficiency and toxic effects (11), is a component of the antioxidant system, and one of the most important trace elements in organisms; Se supplements may be effective anti-cancer agents $(12,13)$. Moreover, Se is a key component of the antioxidant system (14) and substantially contributes to human health. The chemical forms of Se regulate its toxicity, bioavailability and diverse biological effects, including anti-inflammatory, antioxidant and immune effects, and lead to severe tissue damage and health complications (15), and supplementation with Se improves the redox system, promotes proper immune system function and has anticarcinogenic effects (16). Se deficiency leads to heart disease, hypothyroidism and a weakened immune system, but excess exposure to Se results in gastrointestinal disturbance 
and hair and nail changes $(17,18)$. Se enhances the function of the immune system, improves proliferation and biofunction of immune system cells and enhances phagocytosis of immune system cells, thereby improving the immune function and ability to resist disease $(19,20)$. In addition, at higher concentrations, Se exhibits pro-oxidant properties that may be a potential mechanism for cancer therapy (21). Furthermore, Se inhibits hepatocyte necrosis and DNA damage by inhibiting cyclophosphamide-induced OS (22).

Previous studies have confirmed that Se may be a promising therapeutic for cancer $(23,24)$, as it promotes the formation of tumor microenvironment that inhibits cancer proliferation. Following cancer surgery, Se supplementation decreases the risk of cancer recurrence, decreases the toxicity and side effects of chemotherapy and radiotherapy and improves the curative effect of anticancer drugs $(25,26)$. Furthermore, Se, as an essential component of selenocysteine-containing proteins, is involved in cellular biochemistry and function (27).

Selenoproteins are essential for human heath, and have been characterized as antioxidant enzymes, protecting against damage caused by free radicals (28). Further studies on selenoprotein gene expression and cytokine content in the chicken thymus have shown that decreased selenoprotein expression levels induce OS $(29,30)$. In addition, Se-containing molecules exhibit antioxidant properties associated with tumor growth, metastasis, angiogenesis and drug resistance (31). For example, Se-methylselenocysteine offers selective protection against toxicity and potentiates the antitumour activity of anticancer drugs (32). An exciting area of drug design research is the synthesis of the polypeptide chelated selenium, which exhibits cancer stem cell line inhibition and antioxidant activity (33). The anticancer bioactive peptide (ACBP) is a low-molecular weight active peptide extracted from goat liver (34). We previously found that ACBP exhibits antineoplastic activity and inhibits tumor growth in nude mice with Dutch gallbladder carcinoma (35). It also increases the chemotherapeutic sensitizing effect and decreases side effects associated with chemotherapy (35). A number of non-natural selenium-containing amino acid derivatives and peptides have been prepared by chemical synthesis to establish an anti-GC system for treating disease (36). Selenocarbohydrates, selenoamino acids and selenopeptides are utilized in the synthesis of biological compounds. To the best of our knowledge, however, associated OS genes and potential antitumor efficacy of synthesized ACBP-chelated selenium [ACBP functionalized selenium (ACBP-S-Se)] particles have not been previously demonstrated. Furthermore, elucidating the molecular mechanism underlying the antioxidant regulatory effects of the peptide-chelated selenium is important for revealing its ability to regulate tumorigenesis and drug resistance. In addition, selenium nanoparticles loaded with anticancer molecules offer a novel strategy for cancer treatment (37). Moreover, lncRNAs regulate OS to maintain homeostasis (38).

Here, sulfhydrylation modifications of ACBP was performed with $\mathrm{S}$-acetylmercaptosuccinic anhydride (S-AMSA) via chemical absorption. Following sulfhydrylation, the binding site of Se was used to link the sulfhydryl group. The molecular mechanism underlying the antioxidant regulation and antitumor effects of ACBP-S-Se on tumor cell lines was investigated in vitro.

\section{Materials and methods}

Materials. ACBP $(8,000 \mathrm{kDa})$ was provided by the Clinical Medicine Research Center of the Affiliated Hospital of Inner Mongolia Medical University (Hohhot, China). S-AMSA (cat. no. 1002008286) and hydroxylamine hydrochloride (cat. no. 1001967036) were purchased from Sigma-Aldrich (Merck $\mathrm{KGaA})$.

Cell culture. Human GC cell lines (MKN-45 and MKN-74) and normal human gastric epithelial cells (GES-1) were purchased from the Institute of Cell Biology of the Chinese Academy of Sciences (Shanghai, China). MKN-74 cells were cultured in DMEM (cat.no. 10566-016, Invitrogen; Thermo Fisher Scientific, Inc.) supplemented with 10\% FBS (cat. no. 10091148; Gibco; Thermo Fisher Scientific, Inc.) and $100 \mathrm{U} / \mathrm{ml}$ penicillin and streptomycin $(\mathrm{P} / \mathrm{S})$ at $37^{\circ} \mathrm{C}$ in a humidified chamber containing $5 \% \mathrm{CO}_{2}$. MKN-45 cells and GES-1 were cultured in RPMI-1640 growth medium (cat. no. 61870036; Invitrogen; Thermo Fisher Scientific, Inc.) supplemented with 10\% FBS (cat. no. 16000-044; Gibco; Thermo Fisher Scientific, Inc.) and $100 \mathrm{U} / \mathrm{ml} \mathrm{P} / \mathrm{S}$ (cat. no. 15140-122; Gibco; Thermo Fisher Scientific, Inc.) at $37^{\circ} \mathrm{C}$ in a humidified chamber containing $5 \% \mathrm{CO}_{2}$.

Synthesis of ACBP-S-Se particles. Briefly, $2.08 \mathrm{~g}$ 3-morpholine-propanosulfonic acid (MOPS; cat. no. 1001878657, Sigma-Aldrich; Merck KGaA) was dissolved in $\mathrm{dd}_{2} \mathrm{O}$ $(200 \mathrm{ml})$ to prepare MOPS-buffered solution. ACBP (1 g) was dissolved in MOPS solution with a $\mathrm{pH}$ of 7.4 to obtain ACBP solution. Then, $0.4 \mathrm{~g} \mathrm{~S}$-AMSA was added to the ACBP solution and incubated at $25^{\circ} \mathrm{C}$ for $2 \mathrm{~h}$, during which $\mathrm{pH}$ was maintained at 7.4. The sample was stored in nitrogen to avoid air oxidation products. Then, $0.05 \mathrm{~mol} / 1$ hydroxylamine hydrochloride was added and the reaction proceeded at $25^{\circ} \mathrm{C}$ for $3 \mathrm{~h}$. Next, $0.66 \mathrm{~g}$ sodium selenite was added to the ACBP-S solution at $30^{\circ} \mathrm{C}$ for $6 \mathrm{~h}$ to obtain the raw ACBP-S-Se product, and gel chromatography column purification was performed again to produce a pure ACBP-S-Se solution [G250 column; with PBS (pH, $7.4 ; 1 \mathrm{~mol} / \mathrm{l})$ as the mobile phase].

The pure ACBP-S-Se was dried by vacuum refrigeration dryer at $35^{\circ} \mathrm{C}$ for $48 \mathrm{~h}$, then the ACBP-S-Se particles underwent chemical structure characterization.

Fourier transform-infrared (FT-IR) spectroscopic analysis. FT-IR spectra were recorded using a Nicolet FT-IR 5700 spectrophotometer (Thermo Fisher Scientific, Inc.) at $25^{\circ} \mathrm{C}$. Characterization of the components (ACBP and ACBP-S-Se) was performed and the samples were triturated with $\mathrm{KBr}$ at a ratio of 1:100 and pressed into pellets for FT-IR spectroscopic analysis at $500-4,000 \mathrm{~cm}^{-1}$.

$X$-ray photoelectron spectroscopy (XPS). XPS (Thermo Fisher, ESCALAB 250Xi; Thermo Fisher Scientific, Inc.) was used to determine the elemental compositions of ACBP and ACBP-S-Se, for which full (pass energy, $100 \mathrm{eV}$ ) and high-resolution spectra (pass energy, $20 \mathrm{eV}$ ) were recorded.

Particle morphology. The morphology of ACBP-S-Se particles was examined by scanning electron microscopy (SEM) and energy dispersive X-ray spectroscopy (EDX). ACBP-S-Se 
was carefully dried to maintain the surface structure and then mounted, sputter-coated with gold and observed under a Hitachi S-570 SEM microscope (Hitachi, Ltd.) at x200 magnification.

Carbon (13C) and hydrogen $(H)$ nuclear magnetic resonance (NMR) spectra. $\mathrm{H}$ and $13 \mathrm{C}$ NMR spectra were recorded in deuteroxide $\left(\mathrm{D}_{2} \mathrm{O}\right)$ at $17^{\circ} \mathrm{C}$ using a Bruker DRX 500 spectrometer (Bruker Corporation). For each spectrum, $\sim 1,500$ transients were collected using the following acquisition parameters: $3 \mathrm{sec}$ delay between pulses, $90^{\circ}$ pulse for $5.4 \mu \mathrm{sec}$ and $1 \mathrm{~m} \mathrm{sec}$ contact time. Data were acquired and processed using Topspin 2.1 (Bruker Corporation).

Inductively coupled plasma-mass spectrometry (ICP-MS). The Se content in ACBP-S-Se particles was determined by ICP-MS (cat. no. 7900ICP, Agilent Technologies, Inc.) as previously described (39). Following ignition, the tested elements and internal standard (10 bbp TuneA) were set according to the standard model. The parameters were as follows: Collision gas, $\mathrm{H}_{2} / \mathrm{He}$; flow velocity, $5.5 \mathrm{ml} / \mathrm{min}$, Co sensitivity, 20,000 counts per second/parts per billion (ppb). U signal maximum was adjusted and $\mathrm{Se}$ in ACBP-S-Se was measured. The amount of selenium bound to ACBP was determined as follows: $\mathrm{n}_{\mathrm{Se}} / \mathrm{n}_{\mathrm{ACBP}}=\left(\mathrm{m}_{\mathrm{Se}} / \mathrm{M}_{\mathrm{Se}}\right) /\left(\mathrm{m}_{\mathrm{ACBP}} / \mathrm{M}_{\mathrm{ACBP}}\right)=\left(\mathrm{C}_{\mathrm{Se}} / \mathrm{M}_{\mathrm{Se}}\right) /\left(\mathrm{C}_{\mathrm{ACBP}} / \mathrm{M}_{\mathrm{ACBP}}\right)=$ $1,228 \mathrm{C}_{\mathrm{Se}} / \mathrm{C}_{\mathrm{ACBP}}$, where, $\mathrm{n}=$ moles, $\mathrm{m}=$ mass, $\mathrm{M}=$ molar mass, $\mathrm{C}_{\mathrm{Se}}=$ concentration of Se determined by ICP-MS and $\mathrm{C}_{\mathrm{ACBP}}=$ concentration of ACBP determined by Nanodrop 2000C (Thermo Fisher Scientific, Inc.).

Drug treatment. The cell lines were pre-plated in 6-well culture dishes (Corning, Inc.) at a density of $5 \times 10^{5}$ cells/well at $37^{\circ} \mathrm{C}$ in a humidified chamber containing $5 \% \mathrm{CO}_{2}$. Cells were cultured in RPMI-1640 (cat. no. 61870036; Invitrogen; Thermo Fisher Scientific, Inc.) growth medium or DMEM (cat. no. 10566-016, Invitrogen; Thermo Fisher Scientific, Inc.) supplemented with 10\% FBS (cat. no. 16000-044; Gibco; Thermo Fisher Scientific, Inc.) and $100 \mathrm{U} / \mathrm{ml} \mathrm{P/S}$ (cat. no. 15140-122; Gibco; Thermo Fisher Scientific, Inc.) at $37^{\circ} \mathrm{C}$ in a humidified chamber containing $5 \% \mathrm{CO}_{2}$. When the cell confluence reached $70 \%$, drug treatment $(0,5,10,20,40$ and $80 \mathrm{mg} / \mathrm{ml}$ ACBP-S-Se) was performed at $37^{\circ} \mathrm{C}$ for $24 \mathrm{~h}$. Optimization of the ACBP-S-Se concentration was performed as previously described (40).

Cell proliferation. The proliferation of MKN-45 and MKN-74 cells following ACBP-S-Se treatment was assessed using an IncuCyte Live Cell Analysis system (ZOOM; Essen BioScience). Briefly, MKN-45 and MKN-74 cells were inoculated into 96 -well plates at a density of $5 \times 10^{3} /$ well and cultured at $37^{\circ} \mathrm{C}$ for $24 \mathrm{~h}$. Following ACBP-S-Se treatment, the 96 -well plates were placed in the IncuCyte Live Cell workstation and cell proliferation was recorded for $24 \mathrm{~h}$ at intervals of $2 \mathrm{~h}$. Control groups were not treated with ACBP-S-Se $(0 \mathrm{mg} / \mathrm{ml})$; experimental groups were treated with different concentrations of ACBP-S-Se $(5,10,20,40$ and $80 \mathrm{mg} / \mathrm{ml})$ at $37^{\circ} \mathrm{C}$ for $24 \mathrm{~h}$. Degree of cell fusion was counted and cell proliferation rate was calculated by IncuCyte Live Cell Analysis system.

Cell migration. The migration of MKN-45 and MKN-74 cells following ACBP-S-Se treatment was determined using an
IncuCyte Live Cell workstation. Briefly, confluent MKN-45 and MKN-74 cells were inoculated into 96-well plates at a density of $5 \times 10^{4} /$ well with serum-free RPMI-1640 growth medium at $37^{\circ} \mathrm{C}$ for $24 \mathrm{~h}$. Following scratching, cells were placed in the IncuCyte Live Cell workstation and migration was recorded for $36 \mathrm{~h}$ at intervals of $2 \mathrm{~h}$. Control groups were not treated with any additional ACBP-S-Se $(0 \mathrm{mg} / \mathrm{ml})$; experimental groups were treated with different concentrations of ACBP-S-Se $(1$ and $5 \mathrm{mg} / \mathrm{ml})$ at $37^{\circ} \mathrm{C}$. After the assay, the data of the scratch wound healing were calculated using IncuCyte Live Cell Analysis system.

RNA extraction and sequencing. MKN-45 cells $\left(5 \times 10^{5}\right.$ cells/well $)$ were treated with ACBP-S-Se $(5 \mathrm{mg} / \mathrm{ml})$ at $37^{\circ} \mathrm{C}$ for $24 \mathrm{~h}$, then collected to extract RNA. Total RNA was isolated and purified using TRIzol ${ }^{\circledR}$ (cat. no. 15596018; Invitrogen; Thermo Fisher Scientific, Inc.) reagent according to the manufacturer's instructions. The total RNA quantity and purity were analyzed using Agilent 2100 Bioanalyzer and RNA 1000 Nano LabChip kit (both Agilent Technologies, Inc.) with RNA integrity number $>7.0$. Then, $~ 5$ ug total RNA was used to deplete ribosomal RNA using a Ribo-Zero ${ }^{\mathrm{TM}}$ rRNA Removal kit (Illumina, Inc.) according to the manufacturer's instructions. The RNAs were fragmented using divalent cations $94^{\circ} \mathrm{C}$ for $4 \mathrm{~min}$. RNA fragments were reverse-transcribed to create cDNA, which was used to synthesize U-labeled second-stranded DNAs with $E$. coli DNA polymerase I, RNase H and dUTP. A-base was added to the blunt ends of each strand, preparing them for ligation to the indexed adapters. Each adapter contained a T-base overhang for ligating the adapter to the A-tailed fragmented DNA. Single-or dual-index adapters were ligated to the fragments and size selection was performed with AMPureXP beads. Then, U-labeled second-stranded DNAs were treated with heat-labile UDG enzyme at $37^{\circ} \mathrm{C}$ for $10 \mathrm{~min}$. The sequences of the forward and reverse primers are shown in Table I. The ligated products were amplified with PCR using primers as follows: Forward, 5'-AATGATACGGCGACCACCGAGATC TACAC-3' and reverse, 5'-CAAGCAGAAGACGGCATACGA GAT-3'. The thermocycling conditions were: Initial denaturation at $95^{\circ} \mathrm{C}$ for $3 \mathrm{~min} ; 8$ cycles of denaturation at $98^{\circ} \mathrm{C}$ for $15 \mathrm{sec}$, annealing at $60^{\circ} \mathrm{C}$ for $15 \mathrm{sec}$ and extension at $72^{\circ} \mathrm{C}$ for $30 \mathrm{sec}$; and final extension at $72^{\circ} \mathrm{C}$ for $5 \mathrm{~min}$. The average insert size for the final cDNA library was $300 \mathrm{bp}( \pm 50 \mathrm{bp})$. The final library concentration was determined by PCR and then multiplexed in a single sequencing lane for a final volume of $20 \mu \mathrm{l}$ at $10 \mathrm{nM}$ before sequencing. Paired-end sequencing was performed on an Illumina HiSeq 4000 according to the manufacturer's instructions.

Transcript assembly. Firstly, cutadapt-1.10 (41) (cutadapt. readthedocs.io/en/stable/) was used to remove reads that contained adapter contamination and low quality or undetermined bases. The sequence quality was verified using FastQC v0.10.1(42)(bioinformatics.babraham.ac.uk/projects/fastqc/). Then, hisat2-2.0.4 (43) (ccb.jhu.edu/software/hisat2/) was used to map reads to the human genome GRCh38 (ftp. ensembl.org/pub/release-90/fasta/homo_sapiens/dna/Homo_ sapiens.GRCh38.dna.toplevel.fa.gz) (44). All transcriptomes from samples were merged to reconstruct a comprehensive 
Table I. Primers for reverse transcription-quantitative PCR.

\begin{tabular}{ll}
\hline Primer & \multicolumn{1}{c}{ Primer sequence, ${\text { 5' } \rightarrow 3^{\prime}}^{\prime}$} \\
\hline hCDKN1A-F & GGGTGCGGTGATGGATAAA \\
hCDKN1A-R & ACTGCTGAGAACAGGAAGAAC \\
hCCNB1-F & GATGCAGAAGATGGAGCTGAT \\
hCCNB1-R & TCCCGACCCGTGGTTTT \\
hTXN-F & GAAGCTCTGTTTGGTGCTTTG \\
hTXN-R & CTCGTCTGCTTCCCTCTT \\
hMAP3K5-F & CCCAGAGAGAGACAGCAGATA \\
hMAP3K5-R & CTCACTGAAAGAGCCCAGATAC \\
GAPDH-F & TGAACGGGAAGCTCACTG \\
GAPDH-R & GCTTCACCACCTTCTTGATG
\end{tabular}

F, forward; R, reverse; h, human; CDKN1A, CDK inhibitor 1A; CCNB1, cyclin B1; TXN, thioredoxin; MAP3K5, mitogen-activated protein kinase kinase kinase 5.

transcriptome using gffcompare (github.com/gpertea/gffcompare/). After the final transcriptome was generated, StringTie (version no. 1.2.4; ccb.jhu.edu/software/stringtie/) (44) was used to assess mRNA expression levels by calculating fragments per kilobase of transcript per million mapped reads (FPKM) (45) as follows: FPKM=total_exon_ fragments/mapped_reads (millions) x exon_length $(\mathrm{kb})$.

Long non-coding (lnc)RNA identification. Transcripts that overlapped with known mRNAs and transcripts $<200 \mathrm{bp}$ in length were discarded. CPC0.9-r2 (46) (cpc2.cbi.pku.edu.cn/) and CNCI2.0 (47) (bioinfo.org/software/cnci) with default parameters (cpc2-i novel.fa-ocpc2.out and CNCI.py-f novel. fa-o CNCI.result-p 1-mve-g novel.gtf-d genome.fa, respectively) were used to predict transcripts with coding potential. All transcripts with cerebral performance category score $<-1$ and CNCI score $<0$ were removed and remaining transcripts were considered to be IncRNAs.

Differential expression analysis of mRNAs and lncRNAs. StringTie was used to assess expression levels of mRNAs and IncRNAs by calculating FPKM. The differentially expressed mRNAs and lncRNAs were selected with $\log 2$ (fold change) $\geq 1$ or $\log 2$ (fold change) $\leq-1$ and $\mathrm{P}$-value $<0.05$ using $\mathrm{R}$ package edgeR (48) (bioconductor. org/packages/release/bioc/html/edgeR.html/).

Target gene prediction and functional analysis of lncRNAs. To investigate the function of IncRNAs, the cis-target genes of IncRNAs were predicted. IncRNAs may serve a cis role acting on neighboring target genes $(49,50)$. A total of 100,000 up- and downstream coding genes were selected by Python Script (ccb. jhu.edu/software/stringtie/) (51). Then, functional analysis of target genes for lncRNAs with Gene Ontology (GO) and Kyoto Encyclopedia of Genes and Genomes (KEGG) enrichment was performed, as previously described (52).

Reverse transcription-quantitative ( $R T-q) P C R$. Following drug treatment ( 0 and $5 \mathrm{mg} / \mathrm{ml} \mathrm{ACBP}$ ) for $24 \mathrm{~h}$, total RNA was extracted from cells using TRIzol ${ }^{\circledR}$ reagent (cat. no. 15596018; Invitrogen; Thermo Fisher Scientific, Inc.), and cDNA was synthesized according to the manufacturer's instructions using Prime Script ${ }^{\mathrm{TM}}$ RT reagent kit with gDNA Eraser (cat. no. RR047A; Takara Biotechnology Co., Ltd.). The concentration of ACBP was determined based on the cell proliferation rate. For PCR amplification, specific primers were designed using the National Center for Biotechnology Information website (ncbi.nlm.nih.gov) and commercially synthesized by Invitrogen (Thermo Fisher Scientific, Inc.). RT-qPCR was performed on a Thermo Pikoreal machine (Thermo Fisher Scientific, Inc.) with commercial kit (cat. no. RR820A; TB Green ${ }^{\circledR}$ Premix Ex Taq ${ }^{\mathrm{TM}}$ II; Takara Biotechnology Co., Ltd.).

PCR amplification was performed as follows: Initial denaturation cycle for $5 \mathrm{~min}$ at $95^{\circ} \mathrm{C}$, followed by 35 cycles of denaturation at $95^{\circ} \mathrm{C}$ for $30 \mathrm{sec}$, annealing at $58^{\circ} \mathrm{C}$ for $30 \mathrm{sec}$ and extension at $72^{\circ} \mathrm{C}$ for $30 \mathrm{sec}$. The ubiquitously expressed $\beta$-actin gene was used as an internal control. The PCR quantities were confirmed by melting curve analysis and all experiments were performed in triplicate. The relative mRNA expression was calculated using the $2^{-\Delta \Delta \mathrm{Cq}}$ method (53). The primers for RT-qPCR analysis are shown in Table I.

Statistical analysis. Statistical analysis was performed using Graphpad Prism (version no. 6.02; GraphPad Software, Inc.). Data are presented as the mean \pm standard deviation of six independent repeats. Data containing two samples were analyzed using paired Student's t-test. Comparisons in datasets containing $>3$ groups were evaluated by one-way ANOVA followed by Bonferroni's post hoc test. $\mathrm{P}<0.05$ was considered to indicate a statistically significant difference.

\section{Results}

Determination of the chemical structure of ACBP-S-Se by UV and FT-IR spectroscopy. UV absorption value of ACBP was $203 \mathrm{~nm}$ (Fig. 1A). The UV absorption of selenium chelated by ACBP was notable at 206 and $210 \mathrm{~nm}$. New forms of -NH and $-\mathrm{OH}$ were predicted. Weak absorption was observed at $220 \mathrm{~nm}$, and -CNO and -C-S bond formation may have occurred. The absorption intensity of the carbonyl groups were increased because- $\mathrm{NH}$ and $-\mathrm{OH}$ are hydrophilic groups, and the $\lambda_{\max }$ of UV absorption therefore increased from 0.12 to $0.62 \mathrm{~mm}$ (Fig. 1A and C). Compared with the maximum absorption peak of pure ACBP $\left(\lambda_{\max }=206 \mathrm{~nm}\right)$, that of ACBP-S-Se $\left(\lambda_{\max }=210-220 \mathrm{~nm}\right)$ was at a longer wavelength $(4-14 \mathrm{~nm})$. The height of the maximum absorption peak was notably increased for ACBP-S-Se. At 210-220 nm, there were two high absorption peaks, which represented the characteristic absorption peaks of $-\mathrm{C}=\mathrm{O}$, $-\mathrm{NH}$ and $-\mathrm{OH}$ in-RCONHR'. Secondary amide functional groups may have also existed in the product following sulfhydrylation and deacetylation of ACBP. From the FT-IR analysis, distinction between the two maps (ACBP and ACBP-S-Se) was notable, indicating that the ACBP-S-Se curve represented the formation of a new substance that differed from ACBP (Fig. 1B). In the ACBP-S-Se curve, vibrational peaks of the Se-Se bond were observed at 535 and $640 \mathrm{~cm}^{-1}$, and absorption peaks of the C-Se bond were observed at 736.8, 721.0 and $775.0 \mathrm{~cm}^{-1}$. Moreover, the unique absorption peak of Se occurred at $2,336 \mathrm{~cm}^{-1}$, the characteristic absorption peak of-SH occurred 


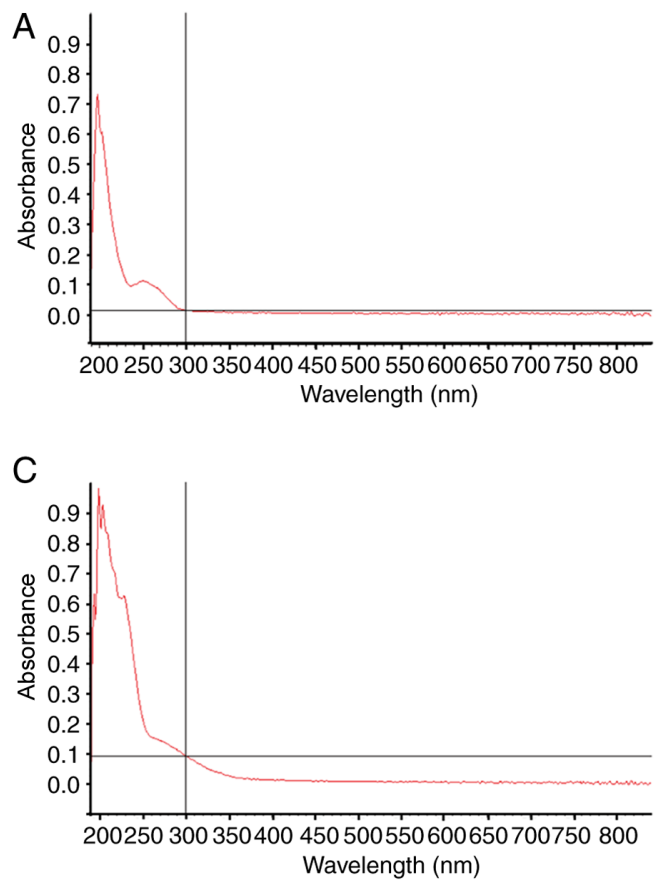

D
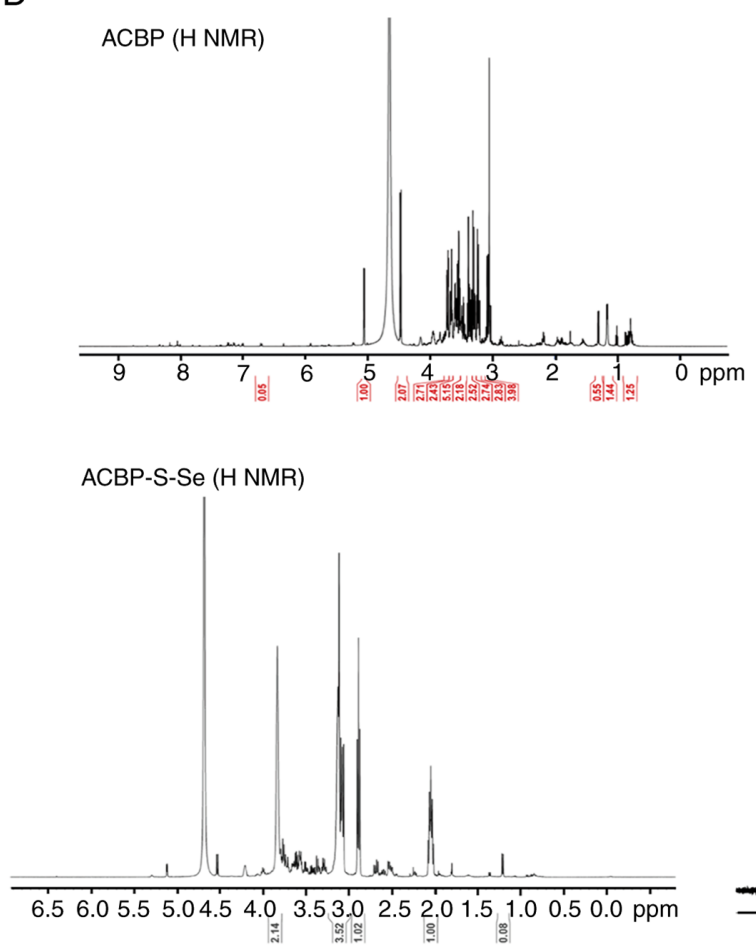
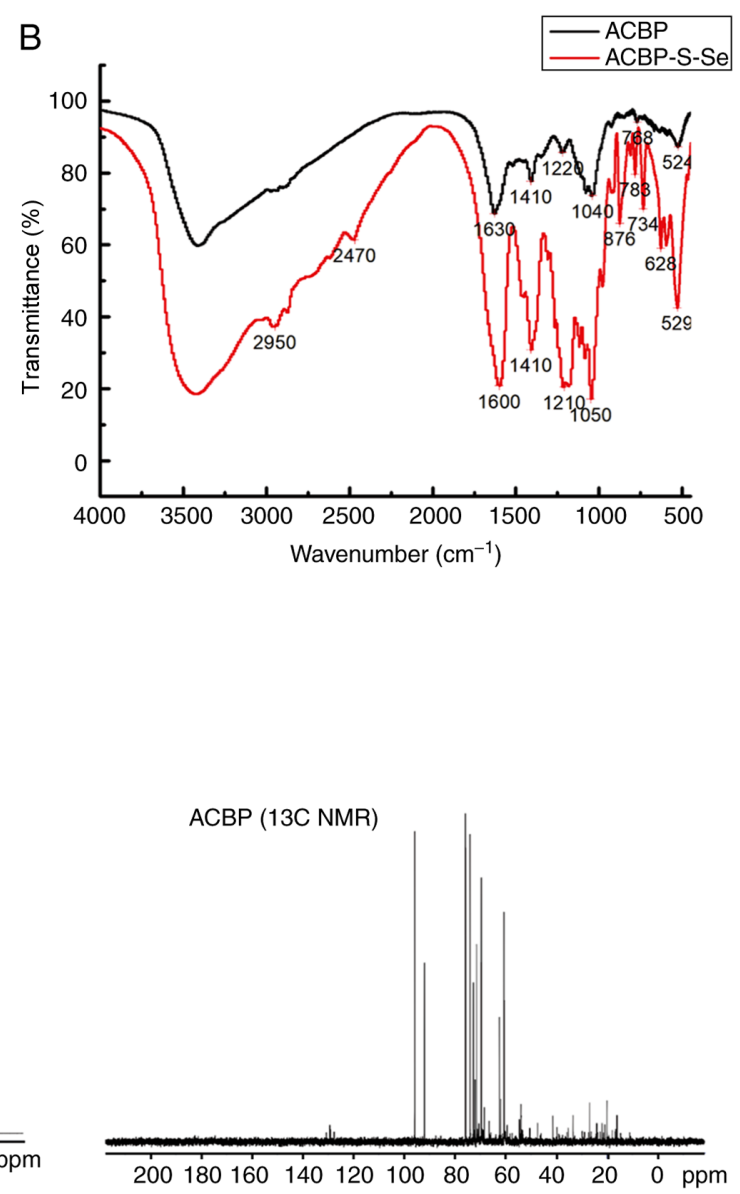

ACBP-S-Se (13C NMR)

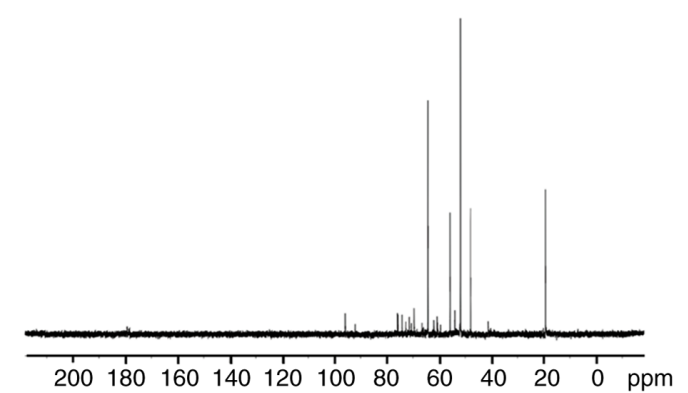

Figure 1. ACBP was characterized by UV, FT-IR and 13C and H NMR. (A) UV spectroscopy of ACBP. (B) FT-IR spectroscopy results of ACBP and ACBP-S-Se. (C) UV spectroscopy of ACBP-S-Se. (D) 13C and H NMR results of ACBP and ACBP-S-Se. UV, ultraviolet; FT-IR, Fourier transform-infrared; NMR, nuclear magnetic resonance; ACBP-S-Se, anticancer bioactive peptide functionalized selenium.

at $2,600 \mathrm{~cm}^{-1}$ and those of secondary amides occurred at 3,391.0, $1,585.5$ and $1,406.2 \mathrm{~cm}^{-1}$. These peaks differed from those in the ACBP curve as the absorption strength was enhanced. These results indicated that ACBP bound with Se to form ACBP-S-Se, and the ACBP chain was linked with sulfhydryl groups by amide bonds to form the ACBP-chelated selenium complex.

Determination of ACBP-S-Se chemical structure by $13 C$ and $H N M R$. In the H NMR spectra, absorption peaks of -OH, -NH and $-\mathrm{SH}$ were detected at the attachments of $\delta 2.31, \delta 6 \sim 8.2$ and $\delta 1.43$, respectively (Fig. 1D). At the same time, different absorption peaks and chemical shifts were observed. In the ACBP spectra, the absorption peak $\delta 2.31$ of $-\mathrm{OH}$ was shifted to $\delta 2.1$ in the ACBP-S-Se spectra. The $\delta 2.93$ of $-\mathrm{SH}-\mathrm{SH}$ absorption peak was observed in the ACBP-S-Se spectra, while no absorption peak of -SH-SH was observed in the ACBP spectra. In the 13C NMR spectra, absorption peaks of $\mathrm{CHO}$ and $-\mathrm{C}-\mathrm{S}$ at $\delta 100$ and absorption peaks of different 
Table II. Assignment of the primary special bands in ACBP-S-Se based on binding energy.

\begin{tabular}{lccl}
\hline Element & ACBP/eV & ACBP-S-Se/eV & \multicolumn{1}{c}{ Assignment } \\
\hline $\mathrm{C} 1 \mathrm{~s}$ & 284.70 & 284.87 & $\mathrm{C}-\mathrm{C}$ \\
$\mathrm{N}$ 1s & 399.65 & 399.02 & $\mathrm{NH}_{2}, \mathrm{NH}_{3}^{+}$ \\
$\mathrm{S} \mathrm{2p}$ & 166.80 & 167.57 & $\mathrm{NO}_{2} \mathrm{SO}_{3}, \mathrm{~K}_{2} \mathrm{SO}_{3}, \mathrm{pNH}_{2} \mathrm{C}_{6} \mathrm{H}_{4} \mathrm{SO}_{2} \mathrm{C}_{6} \mathrm{H}_{4} \mathrm{NH}_{2}^{+}$ \\
$\mathrm{Se} \mathrm{3d}$ & - & 56.20 & $-\mathrm{SH}_{2} \mathrm{Se}$ \\
\hline
\end{tabular}

ACBP-S-Se, anticancer bioactive peptide functionalized selenium.
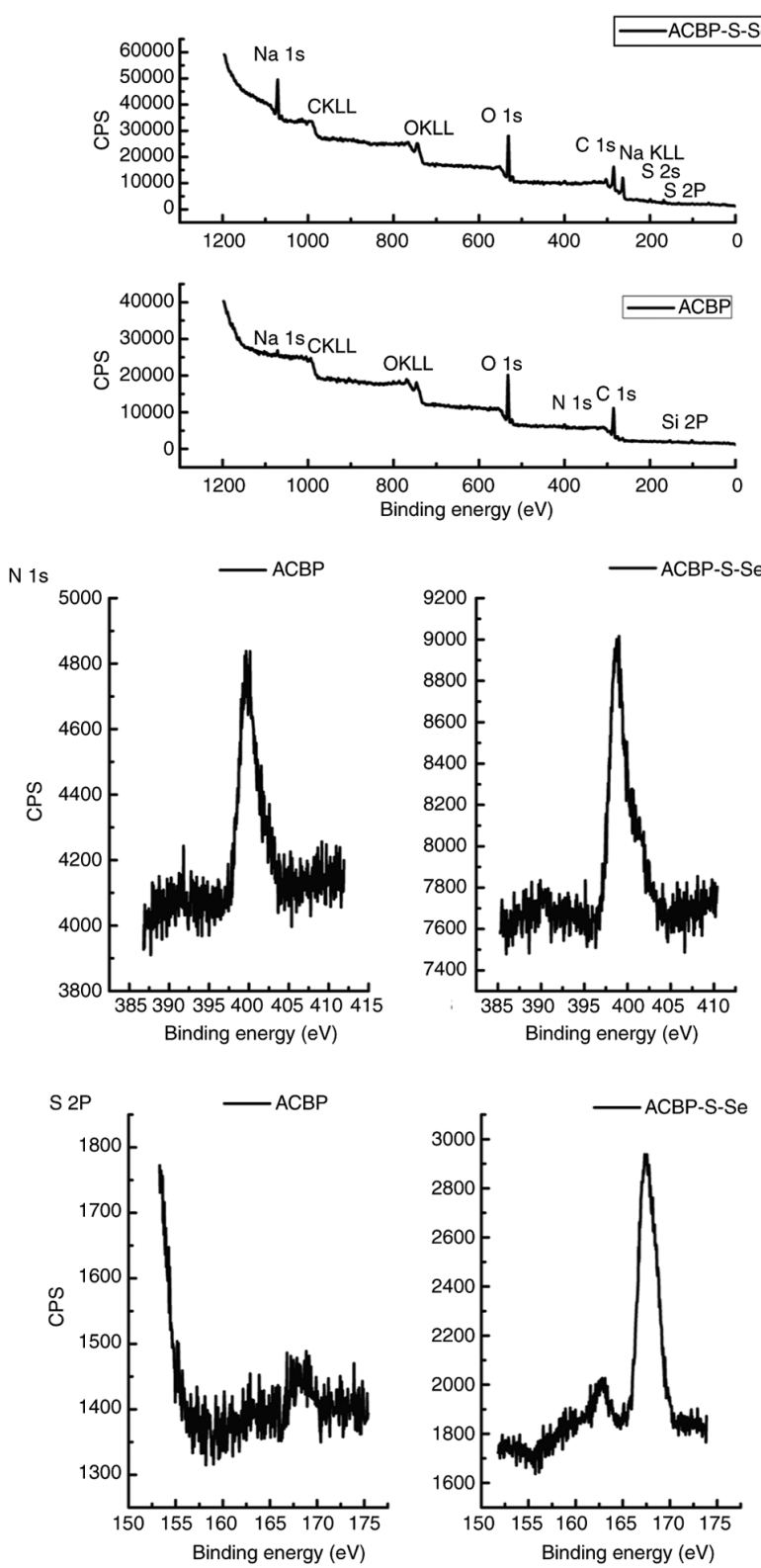
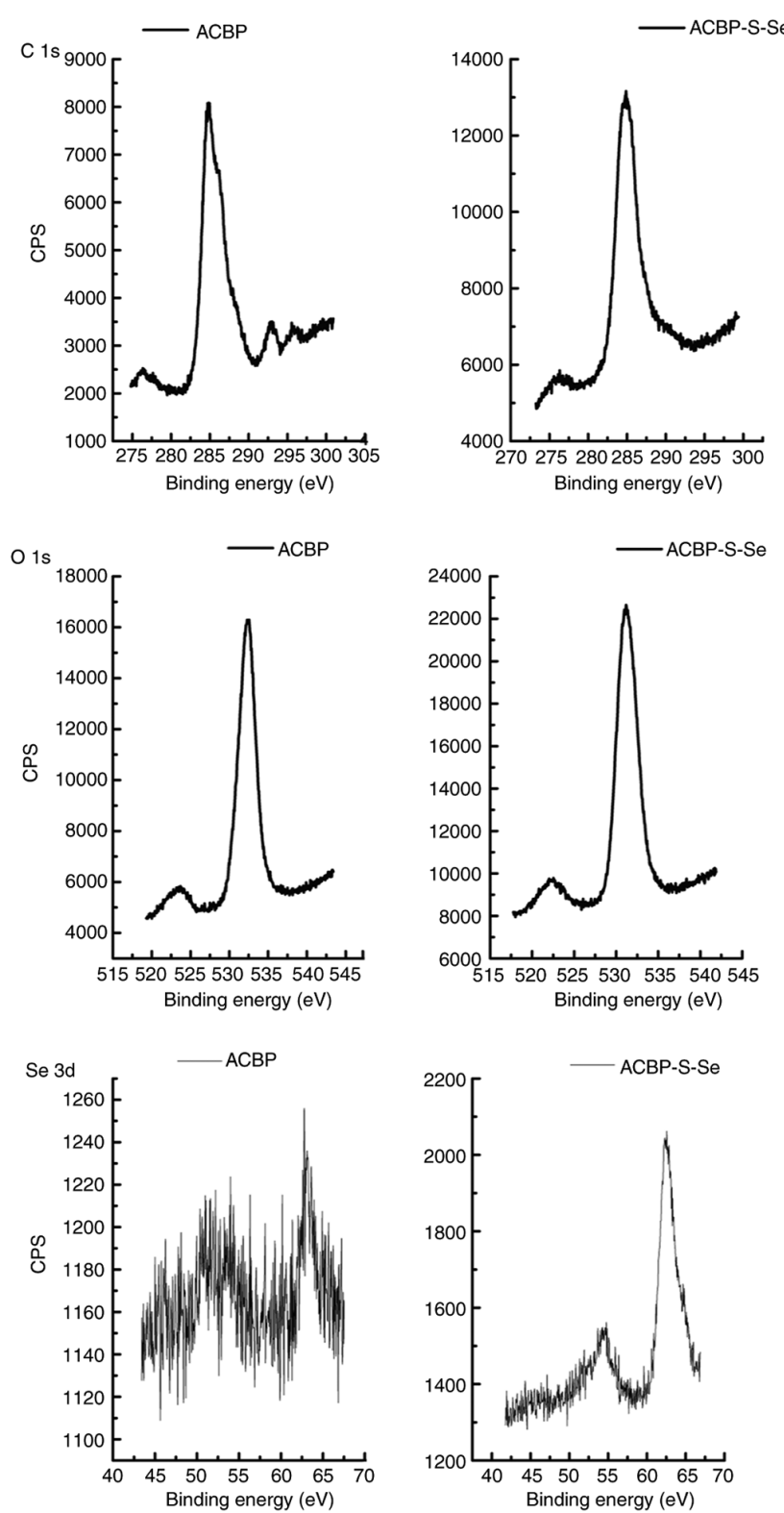

Figure 2. Elemental characterization of ACBP by XPS. XPS results of ACBP-S-Se, including C, N, O, S and Se elements. ACBP-S-Se, anticancer bioactive peptide functionalized selenium; XPS, X-ray photoelectron spectroscopy; CPS, counts per second.

degrees were simultaneously observed. The absorption peak of $-\mathrm{Se}-\mathrm{C}$ was detected at $\delta 180$ with weak absorption peak in the ACBP-S-Se spectra, but no absorption peak of -Se-C was observed in the ACBP spectra. These results showed that binding occurred between the bioactive polypeptide and Se to different extents, and the molecular structure of ACBP-S-Se was thus inferred.

Determination of ACBP-S-Se chemical structure by XPS. Both ACBP and ACBP-S-Se exhibited significant differences 
A
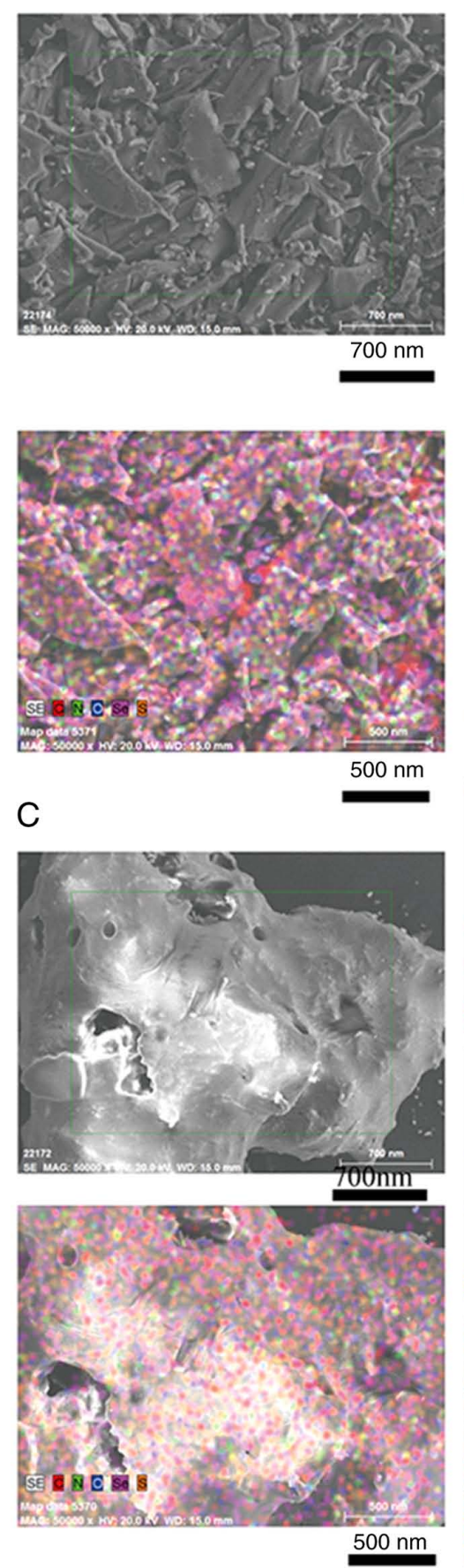
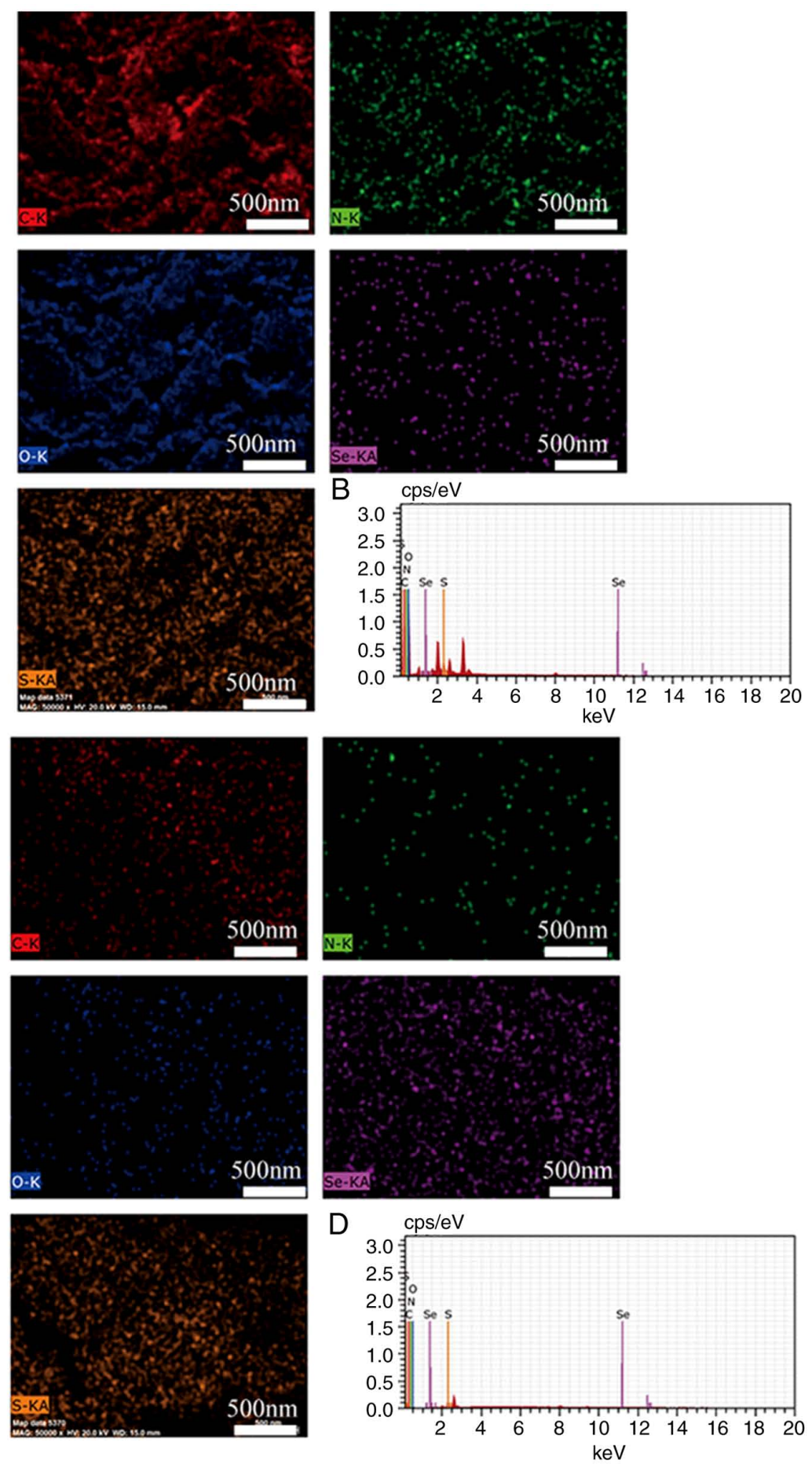

Figure 3. Morphological characterization of ACBP by SEM and EDX. (A) SEM and EDX results (distribution of elements C, N, O, Se, S) and (B) elemental content of ACBP following vacuum freeze-drying. (C) SEM and EDX results (distribution of elements C, N, O, Se, S) and (D) elemental content of ABCP-S-Se. ACBP-S-Se, anticancer bioactive peptide functionalized selenium; SEM, scanning electron microscopy; EDX, energy dispersive X-ray spectroscopy.

in all four peaks in the XPS spectra: C 1s $(284-285 \mathrm{eV}), \mathrm{N} 1 \mathrm{~s}$ (399-400 eV), S 2p (166.80-167.57 eV) and Se 3d (55-60 eV; Table II; Fig. 2). As determined by the XPS spectra of nitrogen, the binding energy decreased from $399.65 \mathrm{eV}$ for ACBP and to $399.02 \mathrm{eV}$ for ACBP-S-Se. However, as determined by the XPS spectra of sulfur, the binding energy increased from $166.8 \mathrm{eV}$ for ACBP and up to $167.57 \mathrm{eV}$ for ACBP-S-Se. Additionally, the binding energy of Se formed at $56.2 \mathrm{eV}$ in ACBP-S-Se and a new-SH=Se bond in ACBP-S-Se was formed, resulting in increased electronegativity of Se $3 \mathrm{~d}$ and binding energy.
SEM-EDX observation and ICP-MS of ACBP-S-Se. ACBP exhibited a coarse fibrous morphological structure (Fig. 3A). According to the morphological analysis of ACBP-S-Se, the particle structure exhibited an average uneven grain that was $5 \mu \mathrm{m}$ in diameter (Fig. 3C). Compared with ACBP, ACBP-S-Se exhibited decreased distribution of elements $\mathrm{C}, \mathrm{N}$ and $\mathrm{O}$ but increased distribution of Se and S (Fig. 3B and D).

Se content reached up to $0.28 \%$ (Fig. 3D). The Se content was $829.030 \mathrm{He} / \mathrm{ppb}$ at an ACBP to Se ratio of 2:1 (Table III). The mole ratio of Se content in the ACBP molecule was 2.1. 
Table III. Concentration of selenium in ACBP chelate selenium as determined by inductively coupled plasma-mass spectrometry.

\begin{tabular}{lcccc}
\hline Sample & Selenium concentration, Se(He)/ppb & ACBP concentration, mg/ml & RSD & nSe/nACBP \\
\hline ACBP:Se (2:1) & 829.03 & 0.05 & 0.3 & 2.1
\end{tabular}

ACBP-S-Se, anticancer bioactive peptide functionalized selenium; RSD, relative standard deviation.

A

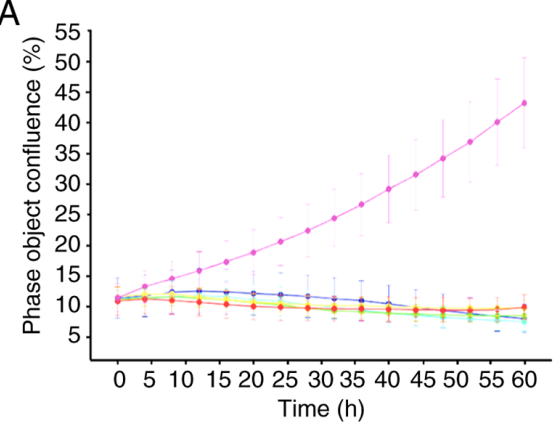

C

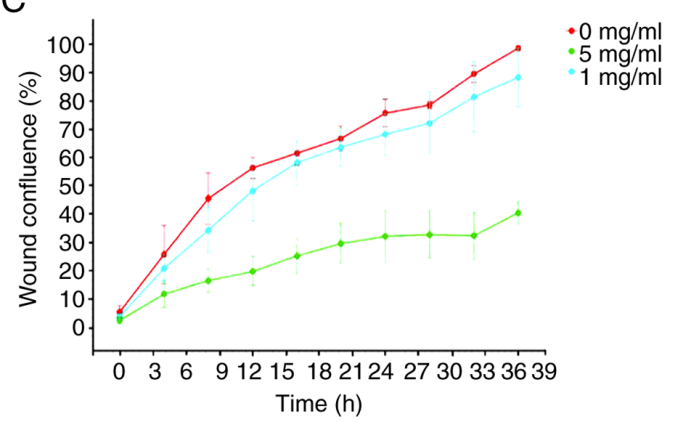

$\mathrm{E}$

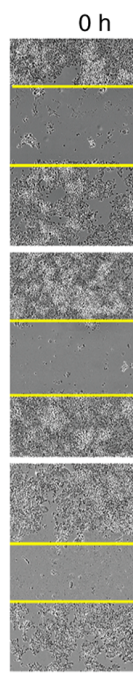

. $5 \mathrm{mg} / \mathrm{ml}$

$10 \mathrm{mg} / \mathrm{ml}$

$20 \mathrm{mg} / \mathrm{m}$

$80 \mathrm{mg} / \mathrm{m}$

$0 \mathrm{mg} / \mathrm{ml}$
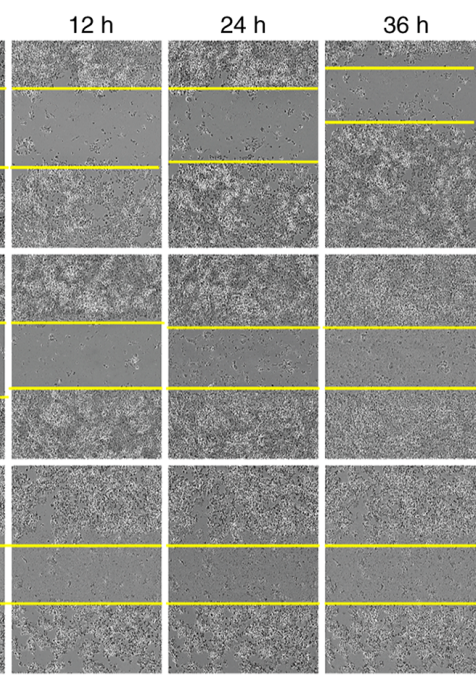

B

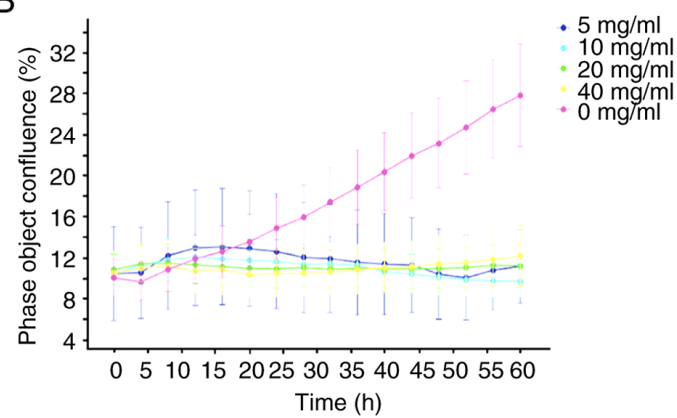

D

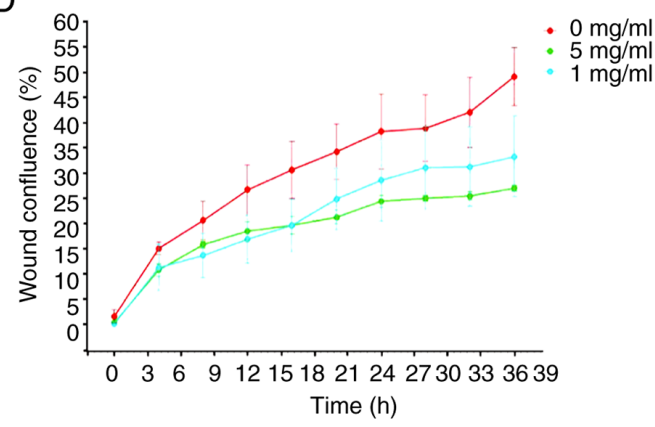

$\mathrm{F}$
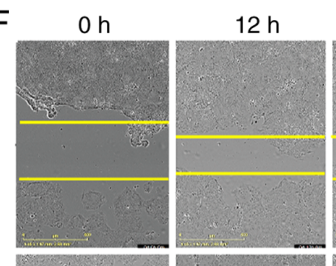

$24 \mathrm{~h}$

$36 \mathrm{~h}$

$0 \mathrm{mg} / \mathrm{ml}$
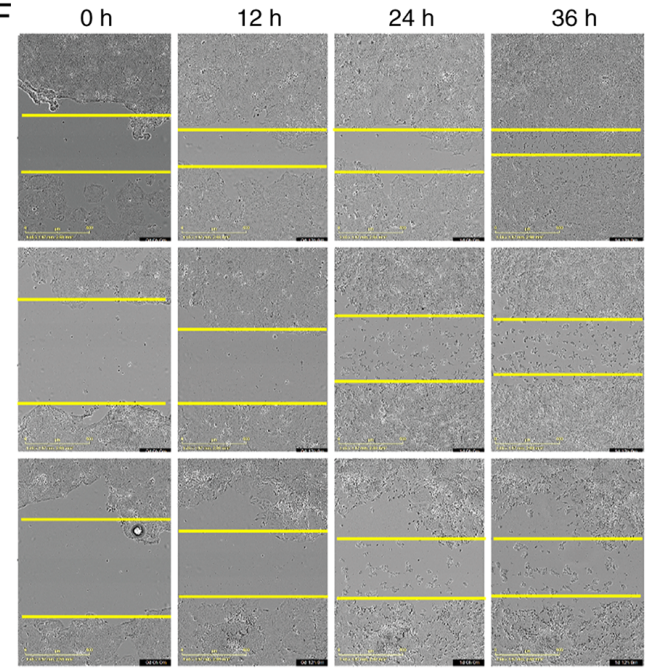

Figure 4. ACBP-S-Se inhibits MKN-45 and MKN-74 cell proliferation. The proliferation of (A) MKN-45 and (B) MKN-74 cells following treatment with ACBP-S-Se was detected using the IncuCyte live cell workstation. Wound healing ability of (C) MKN-45 and (D) MKN-74 cells treated with different concentrations of ACBP-S-Se were detected using the IncuCyte live cell workstation and wound scratch assay. Wound healing assay using (E) MKN-45 and (F) MKN-74 cells. ACBP-S-Se $(0 \mathrm{mg} / \mathrm{ml})$ was used as the control. Magnification, x10. ACBP-S-Se, anticancer bioactive peptide functionalized selenium.

Inhibitory effect of ACBP-S-Se on tumor cell lines. Proliferation of MKN-45 and MKN-74 cells was inhibited following treatment with ACBP-S-Se and the number of cells were inhibited in a dose-dependent manner (Fig. 4A and B). The inhibition of MKN-45 and MKN-74 cell proliferation was not notably different as ACBP-S-Se concentration increased from 5 to $80 \mathrm{mg} / \mathrm{ml}$.

The wound healing ability of MKN-45 and MKN-74 cells decreased following treatment with ACBP-S-Se in a dose-dependent manner (Fig. 4C and D). These results 
Table IV. Screening and enrichment analysis of oxidative stress-associated genes.

\section{Classification}

GO:0006979

GO:0008631

GO:0034599

GO:0036475

GO:0043619

GO:0097193

GO:1900407

GO:1900408

GO: 1902175

GO:1902176

GO:1902882

GO: 1902883

GO: 1903202

GO: 1903204

GO: 1903376

GO: 1903377

hsa04068

hsa04115

\section{Characterization}

\section{Response to oxidative stress}

Intrinsic apoptotic signaling pathway in response to oxidative stress

Cellular response to oxidative stress

Neuron death in response to oxidative stress

Regulation of transcription from RNA polymerase II promoter in response to oxidative stress Intrinsic apoptotic signaling pathway

Regulation of cellular response to oxidative stress

Negative regulation of cellular response to oxidative stress

Regulation of oxidative stress-induced intrinsic apoptotic signaling pathway

Negative regulation of oxidative stress-induced intrinsic apoptotic signaling pathway

Regulation of response to oxidative stress

Negative regulation of response to oxidative stress

Negative regulation of oxidative stress-induced cell death

Negative regulation of oxidative stress-induced neuron death

Regulation of oxidative stress-induced neuron intrinsic apoptotic signaling pathway

Negative regulation of oxidative stress-induced neuron intrinsic apoptotic signaling pathway

FoxO signaling pathway

p53 signaling pathway
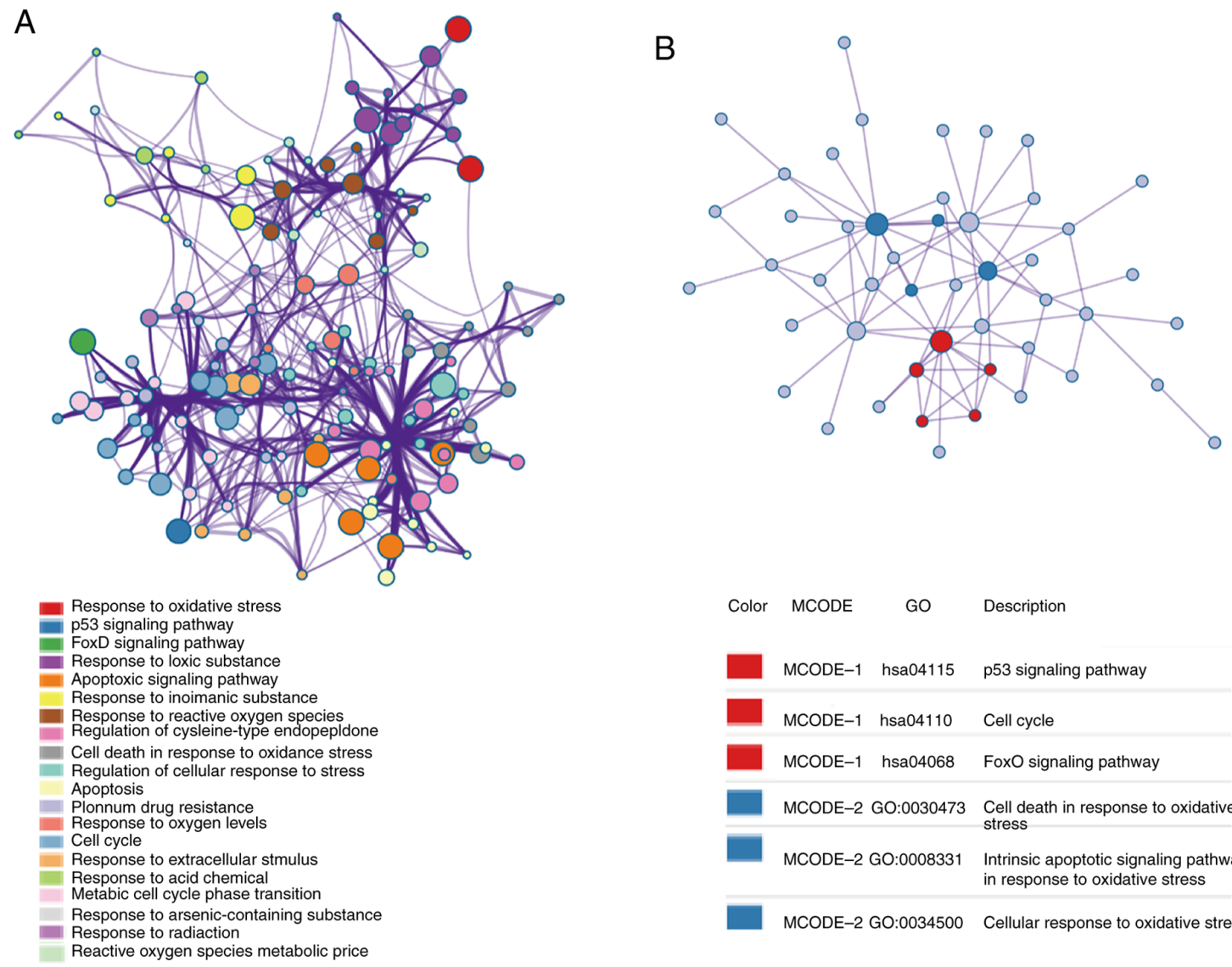

Figure 5. Functional enrichment and oxidative stress-associated genes of anticancer bioactive peptide functionalized selenium. (A) Functional enrichment and association network diagrams of oxidative stress-associated genes (colors represent functions; larger dots indicate more enriched genes; thicker lines indicate more genes with the same function). (B) Interaction of oxidative stress-associated genes (points represent genes; larger circles indicate more genes). GO, Gene Ontology.

indicated that ACBP-S-Se at concentrations from 1 to $5 \mathrm{mg} / \mathrm{ml}$ inhibited cell migration (Fig. 4E and F).
Functional gene selection. Functional gene analysis revealed 911 up- and 1,122 downregulated genes following ACBP-S-Se 
Table V. Expression levels of CDKN1A, CCNB1, MAP3K5 and TXN under oxidative stress in The Cancer Genome Atlas.

\begin{tabular}{lcrrrr}
\hline Gene & MKN-45-ACBP & MKN-45 & FC & $\log 2(\mathrm{FC})$ & Regulation \\
\hline CDKN1A & 264.77 & 9.55 & 25.92 & 4.70 & Up \\
CCNB1 & 8.99 & 25.89 & 0.33 & -1.62 & Down \\
MAP3K5 & 0.99 & 2.94 & 0.32 & -1.66 & Down \\
TXN & 38.74 & 74.24 & 0.49 & -1.03 & Down \\
\hline
\end{tabular}

CDKN1A, CDK inhibitor 1A; CCNB1, cyclin B1; MAP3K5, mitogen-activated protein kinase kinase kinase 5; TXN, thioredoxin.

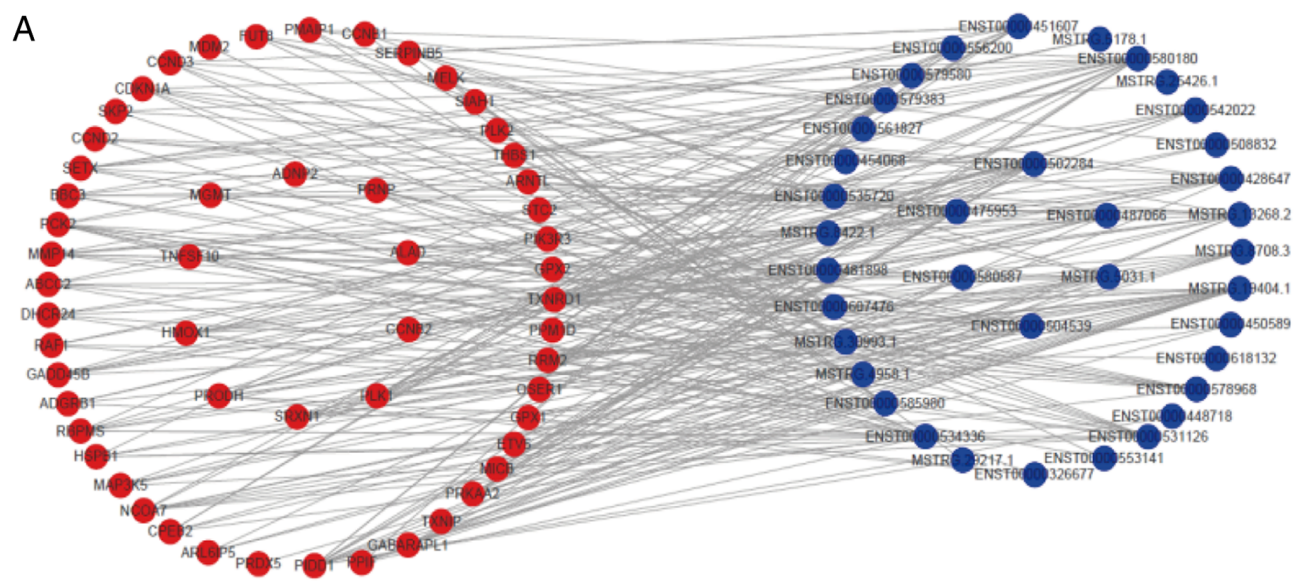

B

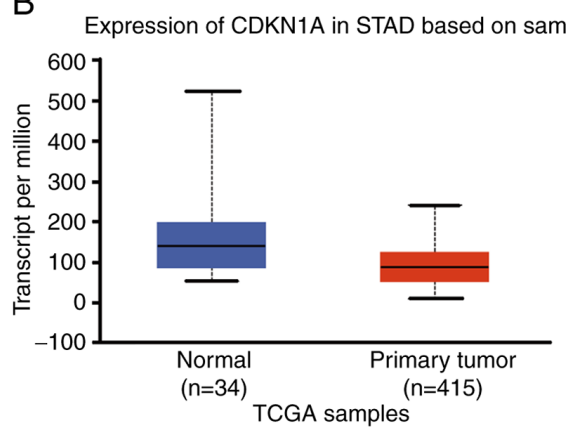

D

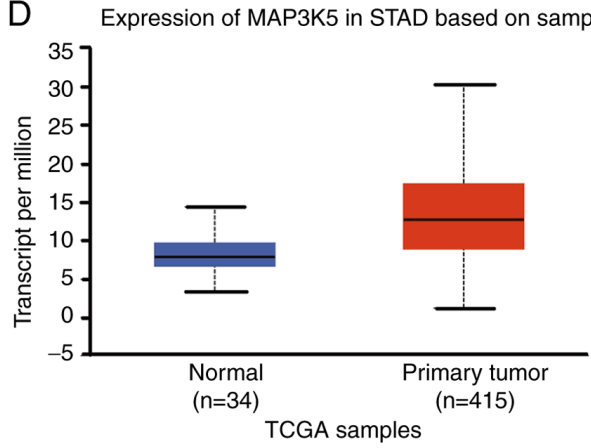

C
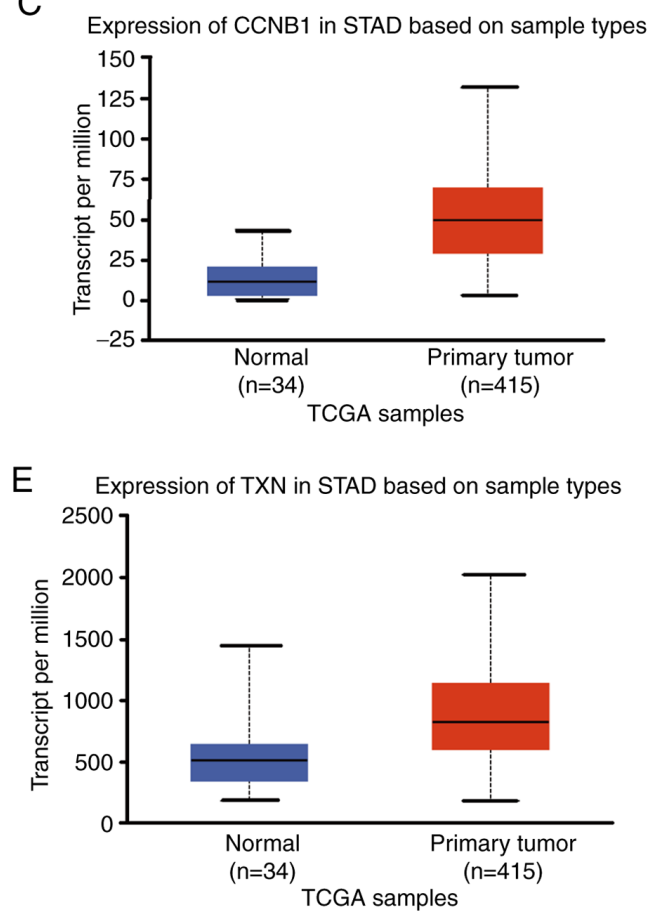

Figure 6. Expression of oxidative stress-associated genes and lncRNAs in normal and primary tumors. (A) Interaction of genes and lncRNAs associated with oxidative stress. Expression levels of (B) CDKN1A, (C) CCNB1, (D) MAP3K5 and (E) TXN in STAD based on TCGA samples (normal and primary tumors). lnc, long non-coding; CDKN1A, CDK inhibitor 1A; CCNB1, cyclin B1; MAP3K5, mitogen-activated protein kinase kinase kinase 5; TXN, thioredoxin; STAD, stomach adenocarcinoma; TCGA, The Cancer Genome Atlas.

treatment in MKN-45 cells. The screening results and enrichment analysis of OS-associated genes are shown in Table IV.

From the functional enrichment analysis of OS-associated genes, a total of 75 genes with significant differences were selected (Fig. 5A). From the gene interaction mapping, CDK inhibitor 1A (CDKN1A), cyclin B1 (CCNB1), thioredoxin (TXN) and mitogen-activated protein kinase kinase kinase 5 (MAP3K5) were extracted based on the roles of genes with 

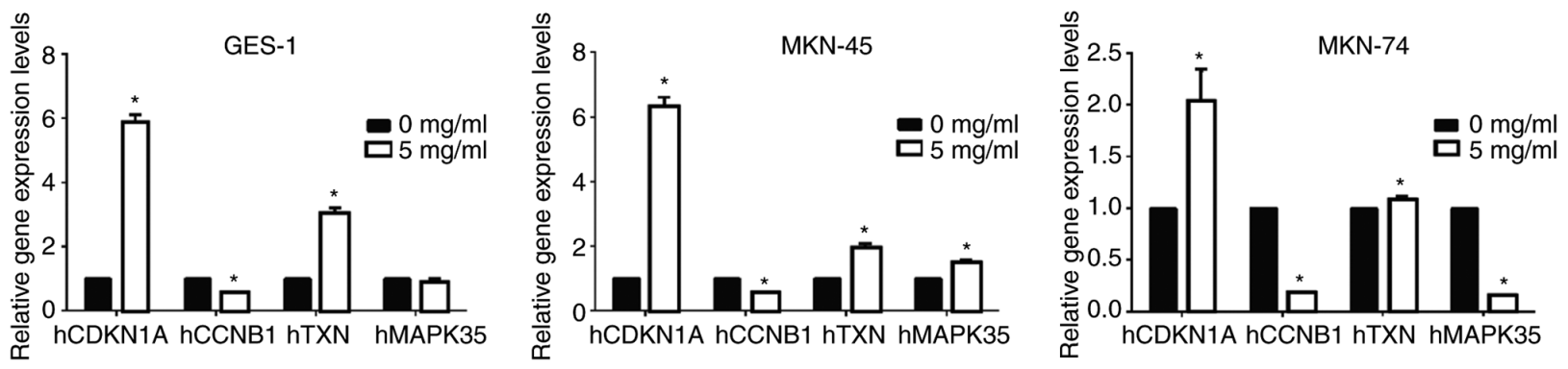

Figure 7. Expression of hCDKN1A, hCCNB1, hTXN and hMAP3K 5 detected by RT-qPCR. The relative hCDKN1A, hCCNB1, hTXN and hMAP3K5 gene expression levels following treatment with $5 \mathrm{mg} / \mathrm{ml}$ ACBP-S-Se were detected by RT-qPCR. ACBP-S-Se $(0 \mathrm{mg} / \mathrm{ml})$ was used as the control. " $\mathrm{P}<0.05 \mathrm{vs}$. control RT-q, reverse transcription-quantitative; h, human; CDKN1A, CDK inhibitor 1A; CCNB1, cyclin B1; MAP3K5, mitogen-activated protein kinase kinase kinase 5; TXN, thioredoxin; ACBP-S-Se, anticancer bioactive peptide functionalized selenium.

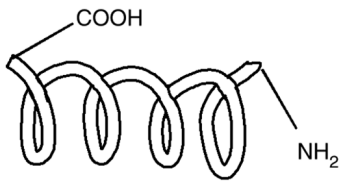

ACBP<smiles>CC(=O)SC1CC(=O)OC1=O</smiles>

S-SAMS

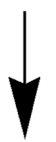<smiles>O=CCC(CC(=O)O)C(=O)Nc1cccc(C(=O)O)c1</smiles>

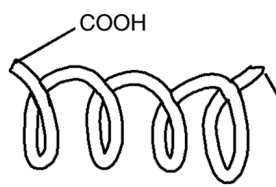

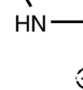<smiles>O=C(O)CC1[Se][Se]=C(C(=O)O)C1C(=O)Nc1cccc(C(=O)O)c1</smiles>

ACBP-S-Se

Figure 8. Mechanism of ACBP, S-SAMS and sodium selenite synthesis. ACBP was subjected to sulfhydrylation modification by S-AMSA and then underwent chelation reactions with sodium selenite. ACBP-S-Se, anticancer bioactive peptide functionalized selenium; S-AMSA, S-acetylmercaptosuccinic anhydride.

which they were associated and the significantly enriched pathways, which were used for TCGA analysis (Fig. 5B).
According to the interaction of genes associated with OS and IncRNAs, networks of OS genes and IncRNA interactions 
(lncRNA FPKM $>5$ ) were constructed via lncRNA trans and cis analysis (TRANS_ENERGY<-50; Fig. 6A). The results showed that the network contained 55 genes associated with OS and 37 lncRNAs.

The selected lncRNAs included MSTRG.13268.2, ENST00000508832, ENST00000580180, ENST00000454068, ENST00000607476, ENST00000504539, ENST00000326677, ENST00000448718, ENST00000531126 and MSTRG.5031.1. Expression levels of the four selected OS-associated genes in The Cancer Genome Atlas (TCGA) were assessed. Expression of CDKN1A increased following treatment with ACBP-S-Se but was lower in tumor samples than in paracancerous samples (Fig. 6B; Table V). The expression of the other three genes decreased following treatment with ACBP-S-Se and was lower in tumor samples than in paracancerous samples, however this was not significantly different.

Relative gene expression levels. CDKN1A, CCNB1, TXN and MAP3K5 gene expression levels in GES-1, MKN-45 and MKN-74 cells were analyzed by RT-qPCR (Fig. 7). In GES-1, MKN-45 and MKN-74 cells, the gene expression levels of CDKN1A and TXN were significantly increased following ACBP-S-Se treatment compared with the control. In addition, the gene expression levels of CDKN1A and TXN in GES-1 cells were significantly different between the control and ACBP-S-Se treatment groups; however, the gene expression levels of MAP3K5 were significantly increased in MKN-45 but decreased in MKN-74 cells following ACBP-S-Se treatment. The results indicated that CDKN1A and TXN protected cells with decrease OS and inhibited cell growth.

\section{Discussion}

GC is a threat to human health worldwide; each year $\sim 990,000$ people are diagnosed with GC worldwide, of whom $\sim 738,000$ die from this disease (54). A previous study demonstrated that ACBP combined with oxaliplatin significantly inhibits proliferation of MKN-45 cells (35). Recently, the replacement of peptides with chemical modifications to achieve the same therapeutic effects as their natural peptide counterparts in combined chemotherapeutics has been developed (55). Furthermore, the incorporation of the Se atom into amino acids and peptides is primarily restricted to selenocysteine derivatives (56) and there is a need to develop synthesis of amino acid-derived chiral Se compounds for evaluation of antioxidant, antihypertensive, anti-inflammatory and immunomodulatory effects (56). Here, ACBP was modified by sulfhydrylation and combined with Se to form ACBP-chelated $\mathrm{Se}$, and its properties and inhibitory effect on GC cells in vitro were investigated.

FT-IR, XPS, 13C and H NMR, SEM, EDX and ICP-MS analysis demonstrated that new functional groups were formed, such as -C-Se, Se-Se, -SH=Se and -CONH. ICP-MS is used to determine the single elements and perform multielement analysis of synthetic drugs (39). The higher content of Se in ACBP-S-Se than in ACBP may indicate that $\mathrm{Se}$ was successfully incorporated into the molecular chain of ACBP. Moreover, Se is a trace element that is beneficial to humans depending on its concentration and chemical speciation $(57,58)$. The mechanism underlying the synthesis of ACBP, S-SAMS and sodium selenite are shown in Fig. 8. Studies have shown that different Se compounds decrease cancer growth, thus serving as potential anticancer drugs $(59,60)$. Se deficiency has been shown to increase cell apoptosis and decrease viability; Se supplementation may mitigate these alterations (28). The present study showed that ACBP-S-Se at $5 \mathrm{mg} / \mathrm{ml}$ effectively inhibited proliferation of MKN-45 and MKN-74 cells. In addition, the wound healing ability of MKN-45 and MKN-74 cells following ACBP-S-Se treatment decreased.

Selenocysteine has high glutathione peroxidase activity and can clear free radicals in the human body (61). Although several functions of selenoproteins are unknown, many disorders are associated with alterations in selenoprotein expression levels or activity (62). Selenium insufficiency and polymorphisms or mutations in genes encoding selenoproteins and synthesis cofactors are involved in the pathophysiology of numerous diseases, including immune disease, GC and colorectal cancer (31). From the perspective of using OS to investigate the competing endogenous RNA mechanism of ACBP-S-Se in the treatment of GC, it is necessary to determine expression changes in OS-associated genes following ACBP-S-Se treatment. Here, analysis of OS-associated pathways and genes resulted in detection of functional genes.

Among these genes, those that were downregulated were determined to encode selenoproteins. Furthermore, Se-specific effects are caused primarily by Se deficiency, rather than high Se levels (63). A total of 75 genes with significantly different functional enrichment were selected, and CDKN1A, CCNB1, TXN and MAP3K5 were selected from the gene interaction map. CDKN1A (also known as p21), a cell cycle-dependent kinase suppressor molecule, protect cells from OS damage (64). CCNB1 also inhibits certain factors in the ubiquitin (Ub) proteasome (65). For example, hydrogen peroxide prevents $\mathrm{Ub}$ from binding to late-promoting complex (anaphase-promoting complex/cyclosome) substrates, which prevents the degradation of $C C N B 1$ and thus inhibited cell proliferation caused by OS. Increased $C C N B 1$ expression has been observed in several types of cancer (66); for example, the expression of CCNB1 in GC tissue is higher than that in normal gastric tissue (67). However, ACBP-S-Se treatment decreased expression levels of CCNB1 in MKN-45 and MKN-74 cells. TXN serves an important role in cellular antioxidant defense $(67,68)$. MAP3K5, also known as apoptotic signal-regulated kinase 1, regulates the biological and physiological processes of apoptosis, immunity and gastric emptying by regulating the flow of apoptotic kinases $(69,70)$. Furthermore, MAP3K5, which is activated in response to stress signals, serves an important role in OS regulation, cell proliferation, differentiation and death and immune response (71). It has been shown that a molecular target of ROS, TXN (also known as Trx), is an inhibitor of MAP3K5 (72). Moreover, oxidation via ROS disrupts the binding of Trx to MAP3K5, resulting in apoptosis (73). The present results showed that formation of ACBP-S-Se negatively regulated MAP3K5 activity, thus attenuating the proapoptotic signal in MKN-74 cells. Inhibition of apoptosis via this mechanism results in increased proliferation and survival, thereby increasing the likelihood of tumorigenesis and/or metastasis. Therefore, OS is associated with the occurrence 
and development of cancer. OS results in cell apoptosis/death, stressors alter micro (mi)RNA expression level profiles and miRNAs serve a role in the cell response to stress (38).

In summary, the application of sulfhydrylation and deacetylation is an effective method to enhance the chelating efficiency of ACBP and Se. According to the UV, FT-IR and 13C NMR, H NMR, XPS, EDX and ICP-MS analysis, Se was chelated to ACBP via sulfhydrylation; the sulfhydryl group was used as the binding site of Se and increased chelation. Finally, the results suggested that ACBP-S-Se effectively inhibited MKN-45 and MKN-74 cell proliferation and migration in vitro and may have clinical applications.

\section{Acknowledgements}

Not applicable.

\section{Funding}

The present study was supported by the National Natural Science Foundation of China (grant nos. 81860416 and 81660468), General Project and Doctor starts of affiliated Hospital of Inner Mongolia Medical University (grant nos. NYFY YB044 and NYFY BS 2018), Inner Mongolia Autonomous Region University 'Youth Science and Technology Talent Support Program' (grant no. NJYT-20-B17) and Scientific and Technological Innovation of College Students in Inner Mongolia Medical University 2020 Project Task of 'Cultivation of Excellence' Project (grant no. YCPY20200033) and Laboratory Open Projects (grant no. 2020ZN47).

\section{Availability of data and materials}

The datasets used and/or analyzed during the current study are available from the corresponding author on reasonable request.

\section{Authors' contributions}

XL, XWa, GL, YX and XS analyzed and interpreted the data. RY, FJ, CS and XWu performed the experiments. XL wrote the manuscript. All authors read and approved the final manuscript. XL and XS confirm the authenticity of all the raw data.

\section{Ethics approval and consent to participate}

Not applicable.

\section{Patient consent for publication}

Not applicable.

\section{Competing interests}

The authors declare that they have no competing interests.

\section{References}

1. Moloney JN and Cotter TG: ROS signalling in the biology of cancer. Semin Cell Dev Biol 80: 50-64, 2018.
2. Huang T, Wang-Johanning F, Zhou F, Kallon $\mathrm{H}$ and Wei Y: MicroRNAs serve as a bridge between oxidative stress and gastric cancer (Review). Int J Oncol 49: 1791-1800, 2016.

3. Ismail T, Kim Y, Lee H, Lee DS and Lee HS: Interplay between mitochondrial peroxiredoxins and ROS in cancer development and progression. Int J Mol Sci 20: 4407, 2019.

4. Zhang P, Shi L, Zhang T, Hong L, He W, Cao P, Shen X, Zheng P, $\mathrm{Xia} Y$ and Zou P: Piperlongumine potentiates the antitumor efficacy of oxaliplatin through ROS induction in gastric cancer cells. Cell Oncol (Dordr) 42: 847-860, 2019.

5. Gu H, Huang T, Shen Y, Liu Y, Zhou F, Jin Y, Sattar H and Wei Y: Reactive oxygen species-mediated tumor microenvironment transformation: The mechanism of radioresistant gastric cancer. Oxid Med Cell Longev 2018: 5801209, 2018.

6. Yu Y, Cui Y, Niedernhofer LJ and Wang Y: Occurrence, biological consequences, and human health relevance of oxidative stress-induced DNA damage. Chem Res Toxicol 29: 2008-2039, 2016.

7. Bao B, Azmi AS, Li Y, Ahmad A, Ali S, Banerjee S, Kong D and Sarkar FH: Targeting CSCs in tumor microenvironment: The potential role of ROS-associated miRNAs in tumor aggressiveness. Curr Stem Cell Res Ther 9: 22-35, 2014.

8. Fuloria S, Subramaniyan V, Karupiah S, Kumari U, Sathasivam K, Meenakshi DU, Wu YS, Sekar M, Chitranshi N, Malviya R, et al: Comprehensive review of methodology to detect reactive oxygen species (ROS) in mammalian species and establish its relationship with antioxidants and cancer. Antioxidants (Basel) 10: 128, 2021.

9. Choudhari SK, Chaudhary M, Gadbail AR, Sharma A and Tekade S: Oxidative and antioxidative mechanisms in oral cancer and precancer: A review. Oral Oncol 50: 10-18, 2014.

10. Kruk $\mathrm{J}$ and Aboul-Enein HY: Reactive oxygen and nitrogen species in carcinogenesis: Implications of oxidative stress on the progression and development of several cancer types. Mini Rev Med Chem 17: 904-919, 2017.

11. Panhwar A, Tuzen M and Kazi T: Ultrasonic assisted dispersive liquid-liquid microextraction method based on deep eutectic solvent for speciation, preconcentration and determination of selenium species (IV) and (VI) in water and food samples. Talanta 175: 352-358, 2017.

12. Zachariah M, Maamoun H, Milano L, Rayman MP, Meira LB and Agouni A: Endoplasmic reticulum stress and oxidative stress drive endothelial dysfunction induced by high selenium. J Cell Physiol 236: 4348-4359, 2021.

13. Cai X, Wang C, Yu W, Fan W, Wang S, Shen N, Wu P, Li X and Wang F: Selenium exposure and cancer risk: An updated meta-analysis and meta-regression. Sci Rep 6: 19213, 2016.

14. Gheorghiu ML and Badiu C: Selenium involvement in mitochondrial function in thyroid disorders. Hormones (Athens) 19: 25-30, 2020.

15. Liu Q, Zhao X, Ma J, Mu Y, Wang Y, Yang S, Wu Y, Wu F and Zhou Y: Selenium (Se) plays a key role in the biological effects of some viruses: Implications for COVID-19. Environ Res 196: 110984, 2021.

16. Peng H, Zhang N, He M, Chen B and Hu B: Simultaneous speciation analysis of inorganic arsenic, chromium and selenium in environmental waters by 3-(2-aminoethylamino) propyltrimethoxysilane modified multi-wall carbon nanotubes packed microcolumn solid phase extraction and ICP-MS. Talanta 131: 266-272, 2015

17. Colangelo LA, He K, Whooley MA, Daviglus ML, Morris S and Liu K: Selenium exposure and depressive symptoms: The coronary artery risk development in young adults trace element study. Neurotoxicology 41: 167-174, 2014.

18. Zhang N, Fu N, Fang Z, Feng Y and Ke L: Simultaneous multi-channel hydride generation atomic fluorescence spectrometry determination of arsenic, bismuth, tellurium and selenium in tea leaves. Food Chem 124: 1185-1188, 2011.

19. Achilli C, Ciana A and Minetti G: Brain, immune system and selenium: A starting point for a new diagnostic marker for Alzheimer's disease? Perspect Public Health 138: 223-226, 2018.

20. Avery JC and Hoffmann PR: Selenium, selenoproteins, and immunity. Nutrients 10: 1203, 2018.

21. Guo CH, Hsia S, Hsiung DY and Chen PC: Supplementation with Selenium yeast on the prooxidant-antioxidant activities and anti-tumor effects in breast tumor xenograft-bearing mice. J Nutr Biochem 26: 1568-1579, 2015.

22. Li B, Li W, Tian Y, Guo S, Qian L, Xu D and Cao N: Selenium-alleviated hepatocyte necrosis and DNA damage in cyclophosphamide-treated geese by mitigating oxidative stress. Biol Trace Elem Res 193: 508-516, 2020. 
23. Salonen JT: Selenium and human cancer. Ann Clin Res 18: 18-21, 1986.

24. Vinceti M, Filippini T, Cilloni S and Crespi CM: The epidemiology of selenium and human cancer. Adv Cancer Res 136: 1-48, 2017.

25. Sun C, Wang L, Xianyu B, Li T, Gao S and Xu H: Selenoxide elimination manipulate the oxidative stress to improve the antitumor efficacy. Biomaterials 225: 119514, 2019.

26. Wang Y, Liu X, Deng G, Sun J, Yuan H, Li Q, Wang Q and $\mathrm{Lu} \mathrm{J}: \mathrm{Se} @ \mathrm{SiO}_{2}$-FA-CuS nanocomposites for targeted delivery of DOX and nano selenium in synergistic combination of chemophotothermal therapy. Nanoscale 10: 2866-2875, 2018.

27. Hoffmann PR and Berry MJ: The influence of selenium on immune responses. Mol Nutr Food Res 52: 1273-1280, 2008.

28. Zoidis E, Seremelis I, Kontopoulos N and Danezis GP: Selenium-dependent antioxidant enzymes: Actions and properties of selenoproteins. Antioxidants (Basel) 7: 66, 2018.

29. Khoso PA, Yang Z, Liu C and Li S: Selenium deficiency downregulates selenoproteins and suppresses immune function in chicken thymus. Biol Trace Elem Res 167: 48-55, 2015.

30. Khoso PA, Yang Z, Liu C and Li S: Selenoproteins and heat shock proteins play important roles in immunosuppression in the bursa of Fabricius of chickens with selenium deficiency. Cell Stress Chaperones 20: 967-978, 2015.

31. Zakharia Y, Bhattacharya A and Rustum YM: Selenium targets resistance biomarkers enhancing efficacy while reducing toxicity of anti-cancer drugs: Preclinical and clinical development. Oncotarget 9: 10765-10783, 2018.

32. CaoS,DurraniFA,Tóth KandRustum YM:Se-methylselenocysteine offers selective protection against toxicity and potentiates the antitumour activity of anticancer drugs in preclinical animal models. Br J Cancer 110: 1733-1743, 2014

33. Yang Y, Liu N, Deng Y, Zeng Y, Pei J, Bao H and Liu L : A kind of whey protein peptide with antioxidant activity-selenium chelate and its preparation method and application. Patent CN108893514A. Filed July 20, 2018; issued November 27, 2018.

34. Zhang C, Jia S and Su X: Effect of anticancer bioactive peptide on the gene expression of human gastric cancer BGC-823 cells PLoS One 9: e102673, 2014.

35. Li X, Wu H, Ouyang X, Zhang B and Su X: New bioactive peptide reduces the toxicity of chemotherapy drugs and increases drug sensitivity. Oncol Rep 38: 129-140, 2017.

36. Cordeau E, Cantel S, Gagne D, Lebrun A, Martinez J, Subra G and Enjalbal C: Selenazolidine: A selenium containing proline surrogate in peptide science. Org Biomol Chem 14: 8101-8108, 2016.

37. Xia Y, You P, Xu F, Liu J and Xing F: Novel functionalized selenium nanoparticles for enhanced anti-hepatocarcinoma activity in vitro. Nanoscale Res Lett 10: 1051, 2015

38. Nie L, Zhang P, Wang Q, Zhou X and Wang Q: lncRNA-triggered macrophage inflammaging deteriorates age-related diseases. Mediators Inflamm 2019: 4260309, 2019.

39. Mittal M, Kumar K, Anghore D and Rawal RK: ICP-MS Analytical method for identification and detection of elemental impurities. Curr Drug Discov Technol 14: 106-120, 2017.

40. Li X, Xia L, Ouyang X, Suyila Q, Su L and Su X: Bioactive peptides sensitize cells to anticancer effects of oxaliplatin in human colorectal cancer xenografts in nude mice. Protein Pept Lett 26: 512-522, 2019.

41. Kechin A, Boyarskikh U, Kel A and Filipenko M: Cutadapt removes adapter sequences from high-throughput sequencing reads. J Comput Biol 24: 1138-1143, 2017.

42. Beekman R, Chapaprieta V, Russiñol N, Vilarrasa-Blasi R, Verdaguer-Dot N, Martens JHA, Duran-Ferrer M, Kulis M, Serra F, Javierre BM, et al: The reference epigenome and regulatory chromatin landscape of chronic lymphocytic leukemia. Nat Med 24: 868-880, 2018

43. Kim D, Langmead B and Salzberg SL: HISAT: A fast spliced aligner with low memory requirements. Nat Methods 12 : 357-360, 2015

44. Pertea M, Pertea GM, Antonescu CM, Chang TC, Mendell JT and Salzberg SL: StringTie enables improved reconstruction of a transcriptome from RNA-seq reads. Nat Biotechnol 33: 290-295, 2015.

45. Trapnell C, Williams BA, Pertea G, Mortazavi A, Kwan G, van Baren MJ, Salzberg SL, Wold BJ and Pachter L: Transcript assembly and quantification by RNA-Seq reveals unannotated transcripts and isoform switching during cell differentiation. Nat Biotechnol 28: 511-515, 2010.
46. Kong L, Zhang Y, Ye ZQ, Liu XQ, Zhao SQ, Wei L and Gao G: CPC: Assess the protein-coding potential of transcripts using sequence features and support vector machine. Nucleic Acids Res 35 (Web Server Issue): W345-W349, 2007.

47. Sun L, Luo H, Bu D, Zhao G, Yu K, Zhang C, Liu Y, Chen R and Zhao Y: Utilizing sequence intrinsic composition to classify protein-coding and long non-coding transcripts. Nucleic Acids Res 41: e166, 2013.

48. Robinson MD, McCarthy DJ and Smyth GK: edgeR: A bioconductor package for differential expression analysis of digital gene expression data. Bioinformatics 26: 139-140, 2010.

49. Stewart GL, Sage AP, Enfield KSS, Marshall EA, Cohn DE and Lam WL: Deregulation of a Cis-acting lncRNA in non-small cell lung cancer may control HMGA1 expression. Front Genet 11: 615378,2021

50. Statello L, Guo CJ, Chen LL and Huarte M: Gene regulation by long non-coding RNAs and its biological functions. Nat Rev Mol Cell Biol 22: 96-118, 2021.

51. Shi T, Hu W, Hou H, Zhao Z, Shang M and Zhang L: Identification and comparative analysis of long non-coding RNA in the skeletal muscle of two dezhou donkey strains. Genes 11: 508, 2020.

52. Young MD, Wakefield MJ, Smyth GK and Oshlack A: Gene ontology analysis for RNA-seq: Accounting for selection bias. Genome Biol 11: R14, 2010.

53. Liu G, Li S, Yuan H, Hao M, Wurihan, Yun Z, Zhao J, Ma Y and Dai Y: Effect of sodium alginate on mouse ovary vitrification. Theriogenology 113: 78-84, 2018.

54. Ferlay J, Shin HR, Bray F, Forman D, Mathers C and Parkin DM: Estimates of worldwide burden of cancer in 2008: GLOBOCAN 2008. Int J Cancer 127: 2893-2917, 2010.

55. Bolhassani A: Improvements in chemical carriers of proteins and peptides. Cell Biol Int 43: 437-452, 2019.

56. Zhang X, He H, Xiang J, Yin $\mathrm{H}$ and Hou T: Selenium-containing proteins/peptides from plants: A review on the structures and functions. J Agric Food Chem 68: 15061-15073, 2020.

57. Castro Grijalba A, Fiorentini EF and Wuilloud RG: Ionic liquid-assisted separation and determination of selenium species in food and beverage samples by liquid chromatography coupled to hydride generation atomic fluorescence spectrometry. J Chromatogr A 1491: 117-125, 2017.

58. Pedrero $Z$ and Madrid Y: Novel approaches for selenium speciation in foodstuffs and biological specimens: A review. Anal Chim Acta 634: 135-152, 2009.

59. Fu X, Yang Y, Li X, Lai H, Huang Y, He L, Zheng W and Chen T: RGD peptide-conjugated selenium nanoparticles: Antiangiogenesis by suppressing VEGF-VEGFR2-ERK/AKT pathway. Nanomedicine 12: 1627-1639, 2016.

60. Pang KL and Chin KY: Emerging anticancer potentials of selenium on osteosarcoma. Int J Mol Sci 20: 5318, 2019.

61. Luo G, Sun Y, Lu S, Mou Y and Yan G: Selenium-containing polypeptide and its use in medicine, food etc. Patent CN1603338A. Filed August 24, 2004; issued April 6, 2005.

62. Hughes DJ, Kunická T, Schomburg L, Liška V, Swan N and Souček P: Expression of selenoprotein genes and association with selenium status in colorectal adenoma and colorectal cancer. Nutrients 10: 1812, 2018.

63. Sunde RA and Raines AM: Selenium regulation of the selenoprotein and nonselenoprotein transcriptomes in rodents. Adv Nutr 2: 138-150, 2011.

64. Lalem T, Zhang L, Scholz M, Burkhardt R, Saccheti V, Teren A, Thiery J and Devaux Y; Cardiolinc ${ }^{\mathrm{TM}}$ network (www.cardiolinc. org): Cyclin dependent kinase inhibitor $1 \mathrm{C}$ is a female-specific marker of left ventricular function after acute myocardial infarction. Int J Cardiol 274: 319-325, 2019.

65. He J, Yu S, Guo C, Tan L, Song X, Wang M, Wu J, Long Y, Gong D, Zhang R, et al: Polyphyllin I induces autophagy and cell cycle arrest via inhibiting PDK1/Akt/mTOR signal and downregulating cyclin $\mathrm{B} 1$ in human gastric carcinoma HGC-27 cells. Biomed Pharmacother 117: 109189, 2019.

66. Chen EB, Qin X, Peng K, Li Q, Tang C, Wei YC, Yu S, Gan L and Liu TS: HnRNPR-CCNB1/CENPF axis contributes to gastric cancer proliferation and metastasis. Aging (Albany NY) 11: 7473-7491, 2019.

67. Hanschmann EM and Berndt C: Thioredoxin (TXN). In: Encyclopedia of Signaling Molecules. Choi S (ed). Springer, Cham, 2018.

68. Yang J, Hamid S, Cai J, Liu Q, Xu S and Zhang Z: Selenium deficiency-induced thioredoxin suppression and thioredoxin knock down disbalanced insulin responsiveness in chicken cardiomyocytes through PI3K/Akt pathway inhibition. Cell Signal 38: 192-200, 2017. 
69. $\mathrm{Pu} \mathrm{L}$, Zhang LC, Zhang JS, Song X, Wang LG, Liang J, Zhang YB, Liu X, Yan H, Zhang T, et al: Porcine MAP3K5 analysis: Molecular cloning, characterization, tissue expression pattern, and copy number variations associated with residual feed intake. Genet Mol Res 15, 2016.

70. Pressinotti NC, Klocker H, Schäfer G, Luu VD, Ruschhaupt M, Kuner R, Steiner E, Poustka A, Bartsch G and Sültmann H: Differential expression of apoptotic genes PDIA3 and MAP3K5 distinguishes between low- and high-risk prostate cancer. Mol Cancer 8: 130, 2009.

71. Golz S, Brüggemeier U and Geerts A: Diagnostics and therapeutics for diseases associated with mitogen-activated protein kinase kinase kinase 5 (map3k5). FR Patent WO2005114199A1. Filed April 30, 2005; issued December 1, 2005.
72. Tzeng HE, Tsai CH, Chang ZL, Su CM, Wang SW, Hwang WL and Tang $\mathrm{CH}$ : Interleukin-6 induces vascular endothelial growth factor expression and promotes angiogenesis through apoptosis signal-regulating kinase 1 in human osteosarcoma. Biochem Pharmacol 85: 531-540, 2013.

73. Prickett TD, Zerlanko B, Gartner JJ, Parker SCJ, DuttonRegester K, Lin JC, Teer JK, Wei X, Jiang J, Nisc Comparative Sequencing Program, et al: Somatic mutations in MAP3K5 attenuate its proapoptotic function in melanoma through increased binding to thioredoxin. J Invest Dermatol 134: 452-460, 2014.

(i) (9) This work is licensed under a Creative Commons Attribution-NonCommercial-NoDerivatives 4.0 International (CC BY-NC-ND 4.0) License. 